\title{
Thermoresponsive Citrate-Based Graphene Oxide Scaffold Enhances Bone Regeneration from BMP9-Stimulated Adipose-Derived Mesenchymal Stem Cells
}

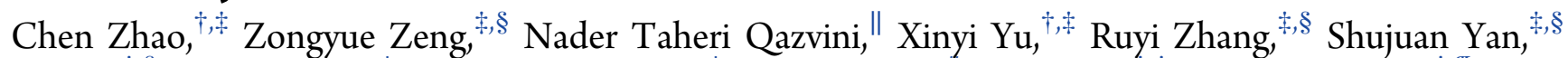
Yi Shu, ${ }^{\ddagger},{ }^{\prime}$ Yunxiao Zhu, ${ }^{\perp, \wedge}$ Chongwen Duan, ${ }^{\perp}$ Elliot Bishop, ${ }^{\sharp}$ Jiayan Lei, ${ }^{\dagger,}$ Wenwen Zhang, ${ }^{\ddagger}, \mathbb{I}$

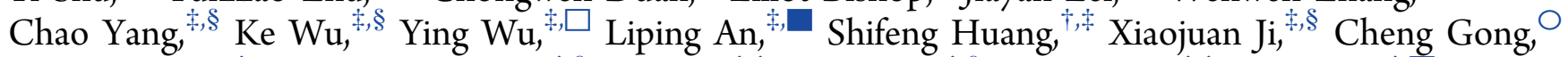
Chengfu Yuan, ${ }^{\ddagger}$ Linghuan Zhang, ${ }^{\ddagger}$, Wei Liu, ${ }^{\dagger, \ddagger}$ Bo Huang, ${ }^{\ddagger}, \S$ Yixiao Feng, ${ }^{\dagger,}$ Bo Zhang, Zhengyu Dai, ${ }^{\ddagger} \triangle$ Yi Shen, ${ }^{\ddagger}, \triangle$ Xi Wang, ${ }^{\ddagger}, \S$ Wenping Luo, ${ }^{\ddagger}$, Leonardo Oliveira, ${ }^{\ddagger}$ Aravind Athiviraham, ${ }^{\ddagger}$ Michael J. Lee, ${ }^{\ddagger}$ Jennifer Moriatis Wolf, Guillermo A. Ameer, ${ }^{\perp, \nabla, \wedge}$ Russell R. Reid, ${ }^{\ddagger}, \#, \wedge$

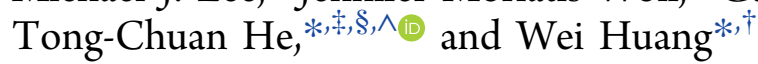

${ }^{\dagger}$ Departments of Orthopedic Surgery, Nephrology, Cardiology, Clinical Laboratory Medicine, and Breast Surgery, The First Affiliated Hospital of Chongqing Medical University, 1 Youyi Road, Chongqing 400016, China

${ }^{*}$ Molecular Oncology Laboratory, Department of Orthopaedic Surgery and Rehabilitation Medicine, The University of Chicago Medical Center, 5841 South Maryland Avenue MC 3079, Chicago, Illinois 60637, United States

${ }^{\S}$ Ministry of Education Key Laboratory of Diagnostic Medicine and School of Laboratory Medicine, The Affiliated Hospitals of Chongqing Medical University, 1 Medical College Road, Chongqing 400016, China

"Institute for Molecular Engineering, The University of Chicago, 5640 South Ellis Avenue, Chicago, Illinois 60637, United States

${ }^{\perp}$ Department of Biomedical Engineering, Northwestern University, 2145 Sheridan Road, Evanston, Illinois 60208, United States

"Department of Surgery, Laboratory of Craniofacial Biology and Development, Section of Plastic Surgery, The University of Chicago Medical Center, 5841 South Maryland Avenue MC6035, Chicago, Illinois 60637, United States

II Department of Laboratory Medicine and Clinical Diagnostics, The Affiliated University-Town Hospital of Chongqing Medical University, 55 Daxuecheng Zhonglu, Chongqing 401331, China

$\square$ Department of Immunology and Microbiology, Beijing University of Chinese Medicine, 11 N. Third Ring Road E., Beijing 100029, China

- Key Laboratory of Orthopaedic Surgery of Gansu Province and the Department of Orthopaedic Surgery, The Second Hospital of Lanzhou University, 82 Cuiyingmen, Lanzhou 730030, China

ODepartment of General Surgery, Zhongnan Hospital of Wuhan University, 169 Donghu Road, Wuhan 430071, China

- Department of Biochemistry and Molecular Biology, China Three Gorges University School of Medicine, 8 Daxue Road, Yichang 443002, China

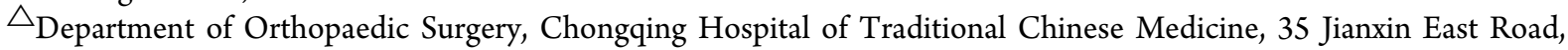
Chongqing 400021, China

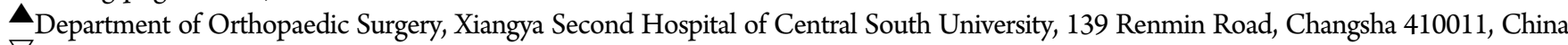

$\nabla$ Department of Surgery, Feinberg School of Medicine, Northwestern University, 420 East Superior Street, Chicago, Illinois 60616, United States

${ }^{\wedge}$ Center for Advanced Regenerative Engineering (CARE), 2145 Sheridan Road, Evanston, IL 60208, United States

\section{Supporting Information}

ABSTRACT: Effective bone tissue engineering is important to overcome the unmet clinical challenges as more than 1.6 million bone grafts are done annually in the United States. Successful bone tissue engineering needs minimally three critical constituents: osteoprogenitor cells, osteogenic factors, and osteoinductive/osteoconductive scaffolds. Osteogenic progenitors are derived from multipotent mesenchymal stem cells (MSCs), which can be prepared from numerous tissue sources, including adipose tissue. We previously showed that BMP9 is the most osteogenic BMP and induces robust bone formation of immortalized mouse adipose-derived MSCs continued...

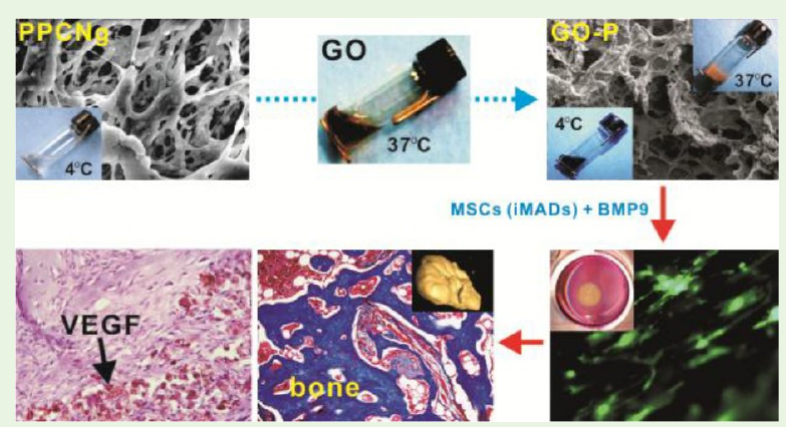

Received: February 13, 2018

Accepted: June 7, 2018

Published: June 7, 2018 
entrapped in a citrate-based thermoresponsive hydrogel referred to as PPCNg. As graphene and its derivatives emerge as promising biomaterials, here we develop a novel thermosensitive and injectable hybrid material by combining graphene oxide (GO) with PPCNg (designated as GO-P) and characterize its ability to promote bone formation. We demonstrate that the thermoresponsive behavior of the hybrid material is maintained while effectively supporting MSC survival and proliferation. Furthermore, GO-P induces early bone-forming marker alkaline phosphatase (ALP) and potentiates BMP9-induced expression of osteogenic regulators and bone markers as well as angiogenic factor VEGF in MSCs. In vivo studies show BMP9-transduced MSCs entrapped in the GO-P scaffold form well-mineralized and highly vascularized trabecular bone. Thus, these results indicate that GO-P hybrid material may function as a new biocompatible, injectable scaffold with osteoinductive and osteoconductive activities for bone regeneration.

KEYWORDS: graphene, graphene oxide, PPCN, thermoresponsive, scaffold, mesenchymal stem cells, BMP9, bone tissue engineering

\section{INTRODUCTION}

Engineering tissues in vitro or in vivo can potentially improve human health by restoring tissue functions that have been compromised by disease or injury. Clinical problems that would benefit from engineered tissues include significant segmental defects, fracture nonunion, and/or medical conditions such as tumor resection and infection sites. ${ }^{1,2}$ In fact, more than 1.6 million bone grafts are done annually in the United States alone. ${ }^{1}$ However, successful regeneration of bone tissue requires a multidisciplinary approach involving the integration of materials science, stem cell biology, biomechanical sciences, and translational medicine as bone has complex structure and its function requires well-orchestrated interactions between cells, the extracellular matrix, biomechanical forces, and gene and protein regulatory factors. ${ }^{1-4}$ Thus, the successful regeneration of bone requires minimally three integral components: osteoprogenitor cells, osteogenic factors, and osteoinductive and/osteoconductive scaffolds. ${ }^{1,2,5-7}$

Osteogenic progenitors are derived from mesenchymal stem cells (MSCs). MSCs are multipotent progenitor cells that are able to self-renew and undergo differentiation into several cell types such as osteogenic, chondrogenic, and adipogenic lineages. ${ }^{3,8-13}$ While bone marrow stromal stem cells are one of the best-studied MSCs, multiple types of MSCs have been isolated from various tissues. ${ }^{10,11,14}$ In particular, adipose tissue has become a favorite source of progenitor cells for tissue regenerative therapies. ${ }^{15-20}$ Adipose-derived mesenchymal stem cells (AD-MSCs) can be isolated from adipose tissue and exhibit osteogenic potential. ${ }^{19,21-23}$ To effectively utilize AD-MSCs as a staple source of cells to form new bone, we have recently established reversibly immortalized mouse adipose-derived MSC (or iMAD) cells, which exhibit the features of multipotent mesenchymal stem cells and respond effectively BMP9 to induce osteogenic differentiation. $^{24}$

Although numerous growth factors and signaling molecules such as Wnts, IGFs, PDGF, FGFs, and Notch play important roles in regulating osteogenic differentiation, ${ }^{3,25-33}$ bone morphogenetic proteins (BMPs) are among the most potent osteoinductive factors. ${ }^{3,4,34,35}$ Through a systematic profiling of the 14 types of BMPs, we demonstrated that BMP9 (or GDF2) is the most potent bone-forming BMP. ${ }^{35-39}$ We further showed that BMP9 induces effective bone formation by regulating several important target genes and lncRNA H19 $9^{40-45}$ and crosstalks with several other critical pathways. ${ }^{46-52}$ Therefore, it is conceivable that the use of BMP9-transduced MSCs should enhance bone regeneration in big osseous defects and fracture nonunion in clinical settings. ${ }^{7,38,39}$

Even though MSCs can be easily identified and isolated, and many biological factors for bone regeneration are now available, successful bone tissue engineering for repairing large defects and fracture nonunion is still a huge clinical challenge, largely due to the lack of ideal scaffolds, which provide cell-friendly microenvironment and solicit efficient in-growth of bone tissue at the repair sites. ${ }^{1,53,54}$ An ideal scaffold can be either osteoconductive, which is supportive for the growth of new bone, and/or osteoinductive, which is able to recruit bone progenitors and stimulate new bone formation. Currently, most of the commonly used scaffolds consist of bioactive glasses, calcium phosphates (in the forms of hydroxyapatite and $\beta$-tricalcium phosphate), and biopolymers. Most of these materials function only as osteoconductive scaffolds for bone in-growth with no or limited osteoinductivity for inducing osteoprogenitor differentiation. ${ }^{1,2,54}$ Thus, it is imperative to develop new scaffolds that possesses osteoinductive and osteoconductive activities for bone tissue engineering., ${ }^{2,54}$

Graphene consists of a single-layer of carbon atoms and has attracted a broad range of interest in many fields, including chemistry, physics, and materials science. ${ }^{55,56}$ Graphene oxide (GO)-based nanomaterials offer multifaceted biomedical applications. GO is hydrophilic and contains ample reactive chemical functionalities, including hydroxyl, carbonyl, carboxyl, and epoxy groups, enabling its surface to be easily modified with biocompatible polymers and enhance its biofunctionalization with higher biocompatibility and more diverse applications in biomedical fields. ${ }^{55,57-61}$ In fact, numerous biomolecules, growth factors, and drugs were coated to GO surface and showed promising biomedical utilities. ${ }^{55-57,61-67}$ GO-derived hybrids were shown to possess a substantial increase in physical properties such as elastic modulus, tensile strength, thermal stability, and electrical conductivity even at low amount of GO filler, essential for an ideal bone tissue engineering scaffold material. ${ }^{56-58,62,65,66,68,69}$ However, the applications of graphene and its derivatives, including GO, in bone tissue engineering are limited. ${ }^{55,56,61,63}$ We recently demonstrated that the thermoresponsive macromolecule PPCN [poly(polyethylene glycol citrateco- $\mathrm{N}$-isopropylacrylamide) $],^{70}$ when mixed with gelatin, served as a highly biocompatible scaffolding material to deliver BMP9-stimulated MSCs for effective bone formation. ${ }^{24,71}$

In this study, we investigated whether incorporating GO into PPCN, the resultant hybrid materials referred to as GO-P, would enhance its ability to support the formation of new bone. We demonstrate that the addition of GO maintains thermoresponsive behavior of the hybrid material and effectively supports MSC survival and proliferation. Furthermore, GO-P induces early bone forming marker alkaline phosphatase (ALP) and potentiates BMP9-regulated osteogenic markers, as well as the angiogenic factor VEGF in MSCs. We further show that BMP9transduced MSCs entrapped in the GO-P scaffold form wellmineralized and highly vascularized trabecular bone. Therefore, the addition of GO renders PPCN osteoinductive and 
angiogenic activities while preserving PPCN's thermoresponsiveness. Thus, our results indicate that the GO-P hybrid material may be used as a novel injectable scaffold with osteoinductive and osteoconductive activities to support the formation of new vascularized bone.

\section{MATERIALS AND METHODS}

Cell Lines and Chemicals. HEK-293 was purchased from ATCC. 293pTP and RAPA lines were derived from HEK-293 as previously described. ${ }^{72,73}$ Mesenchymal progenitor cells, iMADs (immortalized mouse adipose-derived cells), were previously characterized. ${ }^{24}$ These cells were cultured in DMEM with 10\% FBS (Invitrogen, Carlsbad, CA, United States) and cultured in $37^{\circ} \mathrm{C}$ with $5 \%$ CO2. GO $(2 \mathrm{mg} / \mathrm{mL}$ dispersion in $\mathrm{H}_{2} \mathrm{O}$ ) was obtained from Sigma-Aldrich (St. Louis, MO). All other reagents were purchased from ThermoFisher (Waltham, MA) or Sigma-Aldrich.

Preparation of Adenoviral Vectors. AdBMP9, AdR-GLuc, and AdGFP were constructed by using the AdEasy technology as described. ${ }^{7-76}$ Specifically, the coding regions of human BMP9 and Gaussia luciferase were PCR amplified and cloned into a shuttle plasmid, followed by the generation of recombinant adenoviral vectors in BJ5183 bacterial cells. Recombinant adenoviruses were generated and amplified in HEK-293, 293pTP, and/or RAPA cells as previously described, $^{72,73}$ resulting in AdBMP9 and AdR-GLuc, each of which coexpresses GFP and RFP, respectively. An adenoviral vector expressing GFP only (i.e., AdGFP) served as a mock infection control. ${ }^{46,77,78}$ To improve the infection efficiency, polybrene $(5 \mu \mathrm{g} / \mathrm{mL})$ was added to all adenovirus infections as described. ${ }^{79}$

3D Cell Culture of PPCNg and GO-P Hybrid Scaffolds Entrapped with iMAD MSCs. PPCN was synthesized as previously described. ${ }^{70,71}$ PPCN powder was dissolved in PBS (at $100 \mathrm{mg} / \mathrm{mL}$ ), sterilized by syringe filtration with $0.22 \mu \mathrm{m}$ filters, and kept at $4{ }^{\circ} \mathrm{C}$. PPCN-gelatin ( $\mathrm{PPCNg}$ ) was prepared by diluting PPCN stock solution at $1: 1$ ratio with $0.2 \%$ gelatin/PBS (i.e., $\mathrm{PPCN}$ final concentration at $50 \mathrm{mg} / \mathrm{mL}$ ) as described. ${ }^{71}$ Graphene oxide-PPCNg (GO-P) hybrid scaffold was prepared by adding graphene oxide to PPCNg (final concentration at $0.4 \mathrm{mg} / \mathrm{mL}$ ) and mixing well on ice. Unless indicated otherwise, the composition of the GO-P hybrid material was set at PPCNg $(50 \mathrm{mg} / \mathrm{mL}): \mathrm{GO}(2 \mathrm{mg} / \mathrm{mL})=5: 1$ for the reported studies.

For assembling the cell-containing scaffolds, subconfluent iMAD cells were transduced with respective adenoviral vectors at MOI (multiplicity of infection) of 50 for $24 \mathrm{~h}$. The infected cells were collected and resuspended in cold PPCNg or GO-P. The cell-polymer mixtures were placed into cell culture plates that were prechilled at $4{ }^{\circ} \mathrm{C}$ or directly used for subcutaneous injection of athymic nude mice. For in vitro culturing, each well contained $40 \mu \mathrm{L}$ of cell-polymer mixed with $2 \times 10^{5}$ cells. The plates were prewarmed at $37^{\circ} \mathrm{C} 5 \% \mathrm{CO}_{2}$ for $20 \mathrm{~min}$ and then refilled with $2 \mathrm{~mL}$ of the $37^{\circ} \mathrm{C}$ prewarmed complete DMEM. The gels were transferred to new plates after $24 \mathrm{~h}$. Fluorescence signals were recorded under a fluorescence microscope. Each condition was carried out in triplicate.

Rheological Property Analysis. The rheological properties of the PPCNg alone and GO-P hydrogels, with various ratios of PPCNg $(50 \mathrm{mg} / \mathrm{mL})$ vs GO $(2 \mathrm{mg} / \mathrm{mL})$ (e.g., at 10:0, 10:1, 1:1 and 1:10), were characterized by a Discovery Hybrid Rheometer (HR2, TA Instruments, United States). A $2^{\circ}$ stainless steel cone and plate geometry (diameter $20 \mathrm{~mm}$ ) with a truncation gap of $59 \mu \mathrm{m}$ was used. To prevent water loss during measurements, the air around the sample was saturated with water by using a solvent trap filled with a water-soaked sponge. The dynamic moduli (storage, $G^{\prime}$ and loss, $G^{\prime \prime}$ ) were assessed within the linear viscoelastic region as a function of temperature by oscillatory temperature ramp experiments $\left(0.5^{\circ} \mathrm{C} / \mathrm{min}\right)$ at a frequency, $f=1 \mathrm{~Hz}$ and deformation, $\gamma=1 \%$. The linear viscoelastic region was determined by strain sweep measurements.

Gaussia Luciferase (GLuc) Activity Assay. The PPCNg alone and GO-P scaffolds containing with AdR-GLuc infected iMADs were constructed as described above. Fifty microliters of culture medium was taken from each well for GLuc activity assay at the indicated time points by using the BioLux Gaussia Luciferase Assay Kit (NEB) as described. ${ }^{45,80,81}$ All assay conditions were done in triplicate. The culture wells were replenished with the same volume of the $37^{\circ} \mathrm{C}$ prewarmed complete DMEM medium.

Scanning Electron Microscopy (SEM) Analysis. The morphology of the PPCNg and GO-p scaffolds were visualized following the quick-freezing deep etch (QFDE) method as previously described. ${ }^{70}$ Briefly, the PPCNg and GO-P were loaded as room temperature solution directly on the QFDE specimen disks, heated above its LCST until the scaffolds turned solid, and slam frozen in the BioCryo Leica EM HPM100 High-Pressure Freezer. The samples were then dried with the critical point dryer (Leica EM CPD300), loaded onto aluminum SEM pin stub mount using double-sided carbon tape, and imaged with the Nova NanoSEM 230 scanning electron microscope with an accelerating voltage of $5 \mathrm{kV}$ as described. ${ }^{53}$ Each assay condition was carried out in triplicate.

Alkaline Phosphatase (ALP) Activity Assay. The iMADcontaining scaffolds were placed on a preheated electric blanket and washed with prewarmed PBS after the culture medium was completely removed. The scaffolds were then melted at room temperature. The cells were either lysed for quantitative ALP assay or fixed for histochemical staining as described. ${ }^{52,82}$ Each condition was carried out in triplicate.

RNA Isolation and Quantitative Touchdown Real-Time PCR (TqPCR). The iMAD-containing scaffolds were placed on a preheated electric blanket and washed with prewarmed PBS after the medium was completely removed. The cells were lysed in ice-cold TRIzol RNA Isolation Reagent (Invitrogen, Carlsbad, CA, United States) for RNA purification by following the manufacturer's instructions. Total RNA was used for reverse transcription using hexamer and M-MuLV Reverse Transcriptase (New England Biolabs, Ipswich, MA). The RT products were diluted 30-100-fold for TqPCR with mouse gene-specific primers (Table S1), as described. ${ }^{83}$ Briefly, the TqPCR program was set up as previously described. ${ }^{83}$ Gapdh served as a reference gene. Each assay was done in triplicate.

Stem Cell Implantation and Ectopic Bone Formation Using PPCNg and GO-P Hybrid Scaffolds in Vivo. The use and care of animals were approved by the Institutional Animal Care and Use Committee. All experimental procedures were performed in accordance with the approved guidelines. The subcutaneous ectopic bone formation was carried out as previously reported. ${ }^{37,51,84,85}$ Briefly, subconfluent iMADs were infected with AdBMP9 or AdGFP for $36 \mathrm{~h}$, collected and resuspended in $100 \mu \mathrm{L}$ of PPCNg or GO-P scaffolds on ice, and injected into the flanks of athymic mice subcutaneously (Envigo; $n=5$, female, 6-week old; $2 \times 10^{6}$ cells per injection site). At 4 weeks, the animals were sacrificed for harvesting ectopic masses.

Micro-Computed Tomography $(\mu \mathrm{CT})$ Analysis. The retrieved ectopic masses were fixed with 10\% PBS-buffered formalin and subjected to $\mu \mathrm{CT}$ imaging using the GE Triumph Trimodality Preclinical Imaging System (GE Healthcare, Piscataway, NJ, United States). Amira 5.3 (Visage Imaging, Inc., San Diego, CA, United States) was used to perform $3 \mathrm{D}$ reconstruction and determine volumetric data as described. ${ }^{44,47,86}$

Hematoxylin \& Eosin (H\&E) Staining and Trichrome Staining. After $\mu \mathrm{CT}$ imaging, the retrieved masses were decalcified, paraffinembedded, and sectioned. The sections were H\&E and Trichrome stained as previously described. ${ }^{87-89}$ NIH ImageJ was used to quantitatively assess the average $\%$ of trabecular bone area by assessing 10 random high-power fields $(200 \times)$ of $\mathrm{H} \& \mathrm{E}$ staining from each sample group as described. ${ }^{47,49,51}$

Immunohistochemical (IHC) Staining of VEGF Expression. IHC was carried out as described. ${ }^{86,90-92}$ Briefly, the paraffin-embedded tissue sections were deparaffinized, rehydrated, and subjected to IHC staining with a VEGF antibody (mouse, 1:100 dilution; Santa Cruz Biotechnology, Santa Cruz, CA, United States). Sections were then washed and incubated with donkey antimouse IgG antibody conjugated with HRP (Jackson ImmunoResearch Inc., West Grove, PA, United States) for $30 \mathrm{~min}$ at RT. The presence of VEGF was visualized by DAB staining. Stains without the primary antibody were used as negative controls. 
Statistical Analysis. Statistical analysis was conducted as described. ${ }^{93-95}$ Statistical significance was determined by one-way analysis of variance and the Student's $t$ test. A $p$-value $<0.05$ was defined as statistically significant.

\section{RESULTS}

GO Changes the Viscoelastic Properties of the PPCNg. We first tested whether the addition of GO would impact the rheological and viscoelastic properties of PPCNg. When the storage and loss moduli were determined as a function of temperature measured by oscillatory temperature ramp experiments, we found that the PPCNg alone showed a liquid-gel transition at $35^{\circ} \mathrm{C}$, while the GO-P mixture $(1: 1 \mathrm{v} / \mathrm{v})$ exhibited a gel-like structure in both moduli, suggesting that the addition of GO may reduce the liquid phase, likely due to the interactions of particles with the PPCN chains in the mixture (Figure 1A). In fact, the storage modulus of PPCNg increased from 0.06 to $87 \mathrm{~Pa}$ while storage modulus of GO-P (1:1 mix) increased from 8 to $309 \mathrm{~Pa}$ (Figure 1A).

We further determined the optimal GO:PPCN mix ratio by testing the different ratios of PPCN:GO at 10:0, 10:1, 1:1, and $1: 10$ and found that, regardless of the GO compositions, all GO-P mixtures preserved a gel-like structure over the entire temperature range (Figure S1). However, higher GO in the mix resulted in more elastic gels that exhibited weaker temperature dependency (Figure S1). The rapid shift in the moduli may be attributed to the thermal-induced gelation of PPCN chains in the mixture that moves to slightly higher temperatures in the systems with lower PPCN:GO ratios. We chose the PPCNg:GO ratio of 5:1 [i.e., $\mathrm{PPCNg}(50 \mathrm{mg} / \mathrm{mL}): \mathrm{GO}(2 \mathrm{mg} / \mathrm{mL})=5: 1$ ] for the rest of the reported studies.

The physical appearance of GO-P hybrid materials indicated that GO mixed fairly well with PPCNg and remained in liquid form at $4{ }^{\circ} \mathrm{C}$ while gelling rather rapidly at $37^{\circ} \mathrm{C}$, although GO $(0.4 \mathrm{mg} / \mathrm{mL}$ ) always remained in liquid form (Figure $1 \mathrm{~B}, \mathrm{a}$ ). Like the PPCNg, the GO-P hybrid gel formed a solid scaffold material in cell culture medium at $37^{\circ} \mathrm{C}$ (Figure $\left.1 \mathrm{~B}, \mathrm{~b}\right)$. Furthermore, similar to that in PPCNg gel, AdGFP-labeled $\mathrm{iMAD}$ cells were uniformly seeded in the GO-P hybrid scaffold (Figure 1C), indicating that the GO-P hybrid gel may be used as a $3 \mathrm{D}$ culture scaffold.

GO-P Hybrid Scaffold Is Biocompatible and Supports Long-Term Cell Proliferation and Survival. To monitor cell survival and proliferation, we infected subconfluent iMADs with AdR-GLuc, which coexpresses Gaussia luciferase (GLuc) and RFP. When the same number of AdR-GLuc-transduced iMADs was mixed with the same volume of PPCNg or GO-P gel, we found that the RFP signal was compatible in both PPCNg and GO-P gels at day 7 (Figure 2A). However, the RFP signal dropped rapidly in PPCNg gel and became undetectable after day 14, whereas high levels of RFP signal were readily detected in GO-P hybrid scaffold up to day 21 (Figure 2A). Quantitative measurements of the GLuc activities in the culture medium yielded a similar trend, and we found that GLuc activities were consistently higher in the GO-P group than that in the PPCNg group after day 7 and became more pronounced after day 15 after $3 \mathrm{D}$ culture seeding (Figure $2 \mathrm{~B}$ ).

To test whether the decreased RFP signal was caused by the decreased numbers of viable cells or by the dilution of AdR-GLucmediated transient infection, we added a fresh dose of AdR-GLuc to reinfect the $3 \mathrm{D}$ cultured cells and found that more RFP-positive cells reappeared in the GO-P group, while no detectable RFPpositive cells were observed in the PPCNg group (Figure 2C),
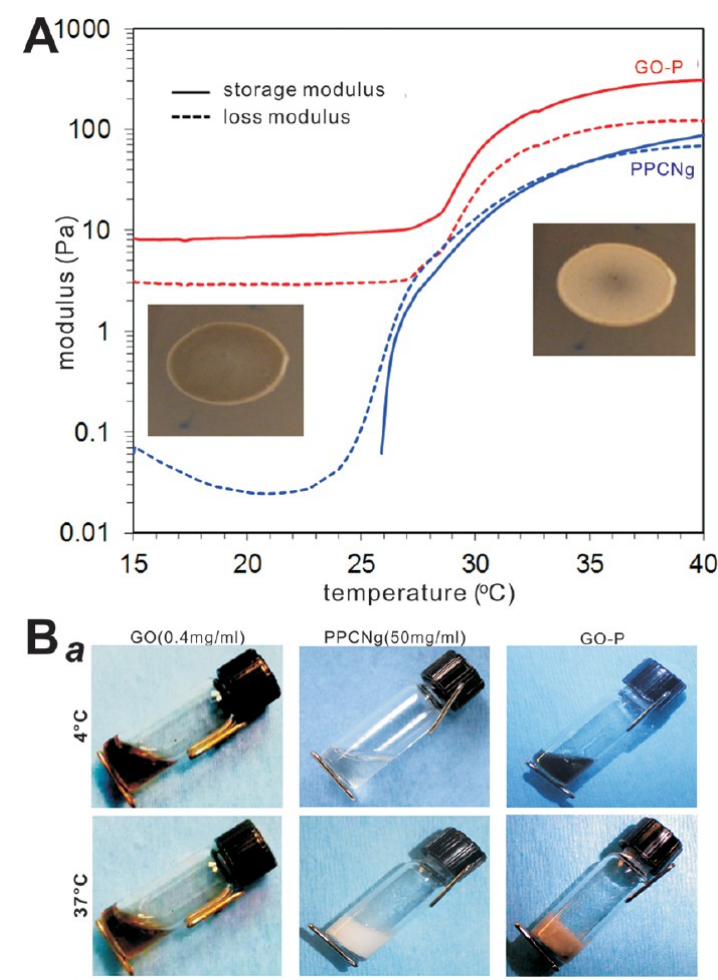

$\boldsymbol{b}$
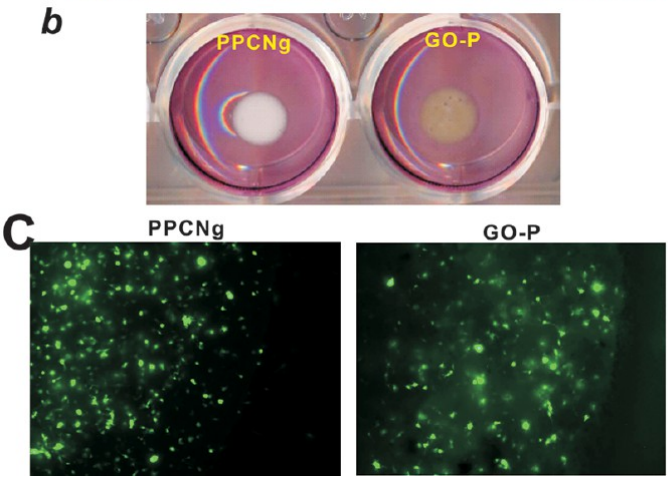

Figure 1. Viscoelastic properties and biocompatibility of GO-P. (A) Temperature evolution of the viscoelastic properties. Variation of storage $\left(G^{\prime}\right)$ and loss $\left(G^{\prime \prime}\right)$ modulus as a function of temperature measured by oscillatory temperature ramp experiments $\left(0.5^{\circ} \mathrm{C} / \mathrm{min}\right)$ at frequency, $f=1 \mathrm{~Hz}$ and deformation, $\gamma=1 \%$. While the PPCNg alone (blue curves) shows a liquid-gel transition at $35^{\circ} \mathrm{C}$, the GO-P mix $(1: 1)$ (red curves) preserves a gel-like structure $\left(G^{\prime}>G^{\prime \prime}\right)$ over the entire temperature range with a jump in both moduli that corresponds to the thermal induced gelation of PPCNg chains in the mixture. Inset: Images of the GO-P sample on the rheometer lower plate at $25^{\circ} \mathrm{C}$ (inset image right) and $37{ }^{\circ} \mathrm{C}$ (inset image left) before and after thermal induced gelation of PPCNg alone, respectively. (B) The physical appearance of GO $(0.4 \mathrm{mg} / \mathrm{mL}), \mathrm{PPCNg}(50 \mathrm{mg} / \mathrm{mL})$, and GO-P hybrid scaffold at 4 and $37^{\circ} \mathrm{C}$ (a) and in culture medium (b). (C) Biocompatibility of PPCNg and GO-P scaffolds. Subconfluent iMADs infected with AdGFP for $16 \mathrm{~h}$ were collected and mixed with PPCNg or GO-P scaffold, followed by seeding in 24-well cell culture plates. At $24 \mathrm{~h}$ after seeding, GFP signal was examined under a fluorescence microscope. Representative images are shown.

suggesting that the GO-P hybrid scaffold may provide a superior 3D environment for cell survival and cell proliferation.

Morphological Features of the Entrapped iMADs and SEM Analysis of the Surface Features of the GO-P Scaffold. We also examined the morphological features of the AdBMP9-transduced iMAD cells seeded in the GO-P scaffold 

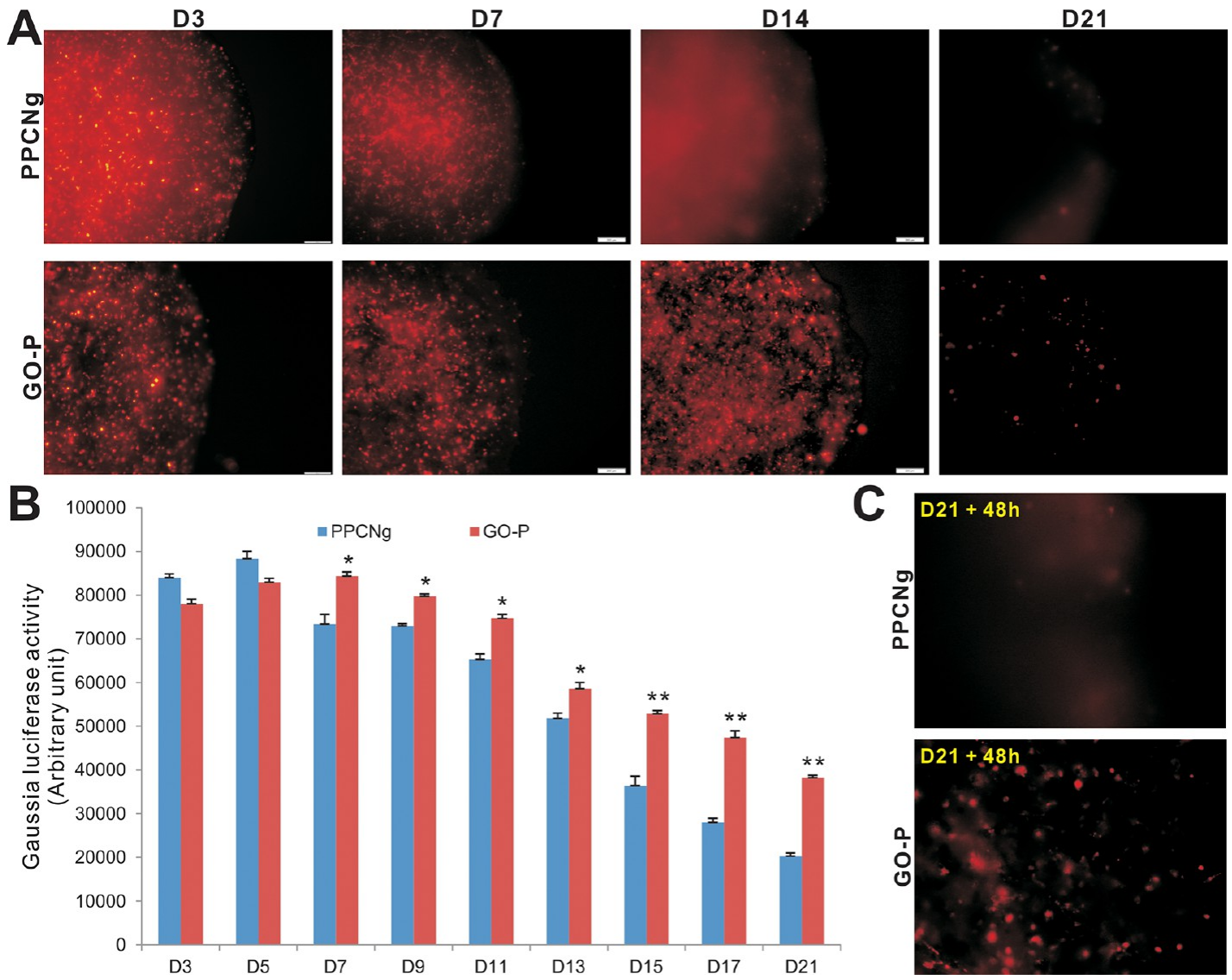

Figure 2. Long-term cell proliferation and survival in GO-P hybrid scaffold in vitro. (A) iMADs were infected with AdR-GLuc, collected, and mixed well with PPCNg or GO-P on ice. The gel mix was then seeded into 24-well cell culture plates that were prewarmed at $37^{\circ} \mathrm{C}$ and cultured in a $37^{\circ} \mathrm{C}$ $\mathrm{CO}_{2}$ incubator for $4 \mathrm{~h}$. The gels were transferred to a fresh set of 24-well plates. RFP signal was recorded at 3, 7, 14, and 21 days. (B) Gaussia luciferase activity of the AdR-GLuc-transduced iMADs entrapped in PPCNg or GO-P scaffolds. At the indicated time points, culture media were collected from PPCNg or GO-P scaffold culture, and GLuc activity was assessed. Each assay condition was done in triplicate. $* p<0.05$, $* * p<0.01$ when compared with that of the GO-P group. (C) Reinfection of the entrapped iMADs in GO-P scaffold. At 21 days of seeding, the above iMAD cell-entrapped scaffolds were infected with AdR-GLuc, and RFP signal was examined at $48 \mathrm{~h}$ after reinfection. Representative images are shown.

and found that the entrapped iMAD cells underwent significant morphological changes and adopted elongated cell shapes at as early as day 1 (Figure 3A), becoming more pronounced at days 3 and 5 (Figure $3 \mathrm{~B}$ and $\mathrm{C}$ ), compared with those in the $\mathrm{PPCNg}$ group. Thus, consistent with the results about the increased viscoelastic properties of PPCN by GO (Figure 1), these results indicate that the GO-P hybrid scaffold may provide a supportive environment for the proliferation and differentiation of MSCs. SEM revealed that the GO-P gel had a rougher scaffold surface when compared to that of PPCNg alone (Figure 4A a and b vs $\mathrm{c}$ and $d$ ). When the AdBMP9-transduced iMADs were seeded in the GO-P hybrid scaffold, the iMAD cells adhered to the surface at day 3 of seeding (Figure 4B, a and b), and significant amounts of minerals were deposited on the surface at day 7 (Figure 4B, $c$ and d).

GO-P Hybrid Scaffold Has Osteoinductive Activity in Vitro. To test whether GO-P hybrid scaffold exhibits osteoinductive activity, we infected iMADs with AdBMP9 or AdGFP and mixed the infected cells with the GO-P gel as well as with the control PPCNg gel, which showed robust adenovirus infection in both types of scaffolds (Figure $5 \mathrm{~A}$, a and $\mathrm{b}$ ). At 5 days after infection, consistent with early reports, ${ }^{3,36-39,84}$ BMP9 was shown to induce a robust level of alkaline phosphatase (ALP) activity in the PPCNg group (Figure 5B). However, the GO-P scaffold treated with AdGFP showed a high level of ALP activity, which was potentiated by BMP9 stimulation (Figure 5B). Furthermore, quantitative analysis revealed that GFP-treated iMADs seeded in the GO-P scaffold (GFP + GOP group) induced significantly high levels of ALP activity at day 5 and day 7, compared with that of the GFP-treated PPCNg group $(p<0.05)$ (Figure 5C). Moreover, BMP9-induced ALP activity was significantly potentiated in the GO-P scaffold when compared with that in the PPCNg gel group (Figure 5C). Thus, these results indicate that the GO-P hybrid scaffold may exhibit both osteoinductive and osteoconductive activities.

GO-P Hybrid Scaffold Potentiates BMP9-Regulated Expression of Osteogenic Markers and Angiogenic Factor and Augments BMP9-Induced Ectopic Bone Formation. To assess the effect of GO-P scaffold on BMP9-induced expression of osteogenic regulators/markers, we infected subconfluent iMAD cells with Ad-GFP or Ad-BMP9 and mixed the cells with PPCNg or GO-P. We revealed that BMP9-induced expression of Runx2 was enhanced in GO-P gel at day 3, while the GFP+ GO-P group also exhibited higher Runx 2 expression at day 5 (Figure 6A). Similarly, AdBMP9-induced Bsp expression was significantly enhanced in the GO-P group, whereas the AdGFPtreated GO-P group also exhibited Bsp expression higher than that of the PPCNg group at both day 3 and day 5 (Figure 6A). Furthermore, the expression of other osteogenic markers such as Osx, Alp, Ocn, Opn, and Colla1 was not only up-regulated by 

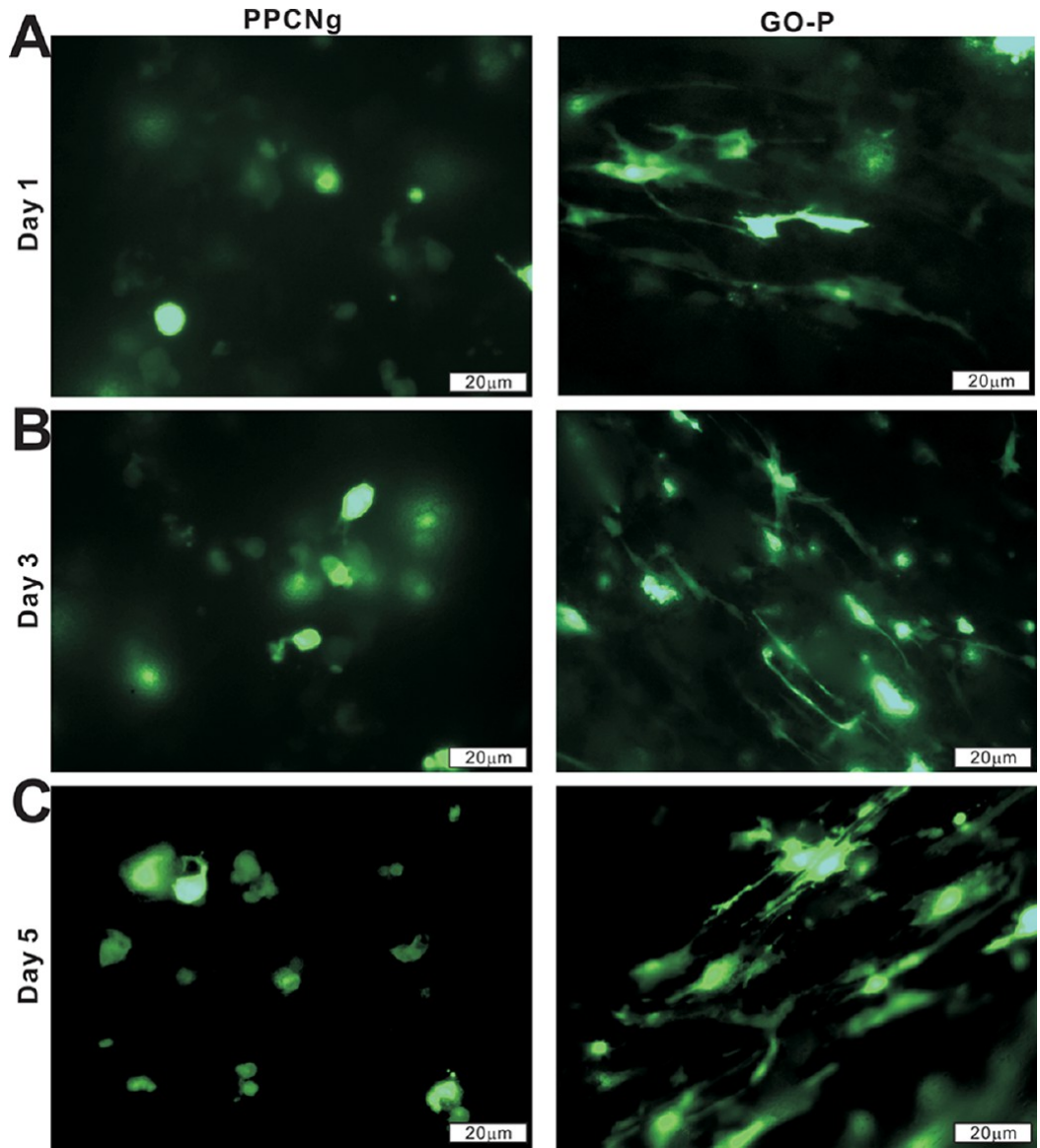

Figure 3. Morphological features of the iMADs entrapped in PPCNg or GO-P scaffolds. Exponentially growing iMADs were first transduced with AdBMP9 and mixed with PPCNg or GO-P scaffold. GFP signals were assessed at 1 day (A), 3 days (B), and 5 days (C) after infection. Representative results are shown. The cells were out of focal planes due to the $3 \mathrm{D}$ culturing conditions on the scaffolds.

BMP9 but also enhanced in AdBMP9-treated GO-P group, compared with that in AdBMP9-treated PPCNg group $(p<0.01)$ (Figure 6B). Similarly, a higher expression level of these osteogenic markers was found in the AdGFP-treated GO-P group than that of AdGFP-treated PPCNg group $(p<0.05)$ (Figure 6B), further suggesting that GO-P hybrid scaffold may exhibit osteoinductive activity. Consistent with our early report that BMP9 is able to induce angiogenic factor $\operatorname{HIF} 1 \alpha,{ }^{49}$ we found that BMP9 was shown to induce the expression of VEGF in the iMADs $(p<0.05)$, which was drastically enhanced in the presence in the GO-P hybrid scaffold (Figure 6B).

Lastly, we determined the in vivo features of the GO-P hybrid scaffold for BMP9-transduced MSCs in ectopic bone formation in athymic nude mice. We found that under the same conditions, the BMP9-transduced iMADs mixed with the GO-P scaffold yielded slightly larger bony masses than that in the $\mathrm{PPCNg}$ group $(p<0.05)$ (Figure 7A, a and b). No detectable bone masses were retrieved from AdGFP-transduced iMAD groups. $\mathrm{H} \& \mathrm{E}$ staining analysis indicated that the bony masses retrieved from the GO-P group exhibit significantly more mature and denser trabecular bone than that from the PPCNg group (Figure 7B, a), which was also confirmed by trichrome staining (Figure 7B, b). A quantitative analysis revealed that the average trabecular bone area was larger in the GO-P group than that in the PPCNg group $(p<0.01)$ (Figure 7C). Furthermore, the histological evaluation indicated that the bony masses from the GO-P group were highly vascularized. We performed immunohistochemical staining to detect VEGF expression in the retrieved bony masses, and significantly higher numbers of VEGF-positive cells were observed in the bony masses retrieved from the GO-P group than that from the PPCNg group (Figure $7 \mathrm{~B}, \mathrm{c}$ ), which is consistent with the qPCR results about marked expression of VEGF induced by BMP9 and GO-P (Figure 6B).

\section{DISCUSSION}

Optimized biocompatible scaffolds are essential to generate healthy bone. Strategies to regenerate bone include the use of cells, signaling molecules, and scaffolds. ${ }^{2}$ We recently demonstrated that a biodegradable thermosensitive $\mathrm{PPCNg}$ can function as a scaffolding delivery carrier of BMP9-transduced MSCs for the formation of well-mineralized and highly vascularized trabecular bone-like structures in a mouse model, ${ }^{24,71}$ suggesting that the PPCN-gelatin may function as a new biodegradable and injectable scaffolding material for stem cell-based bone regenerative tissue engineering.

It is conceivable that biocompatible scaffolds that can sustain cell migration, attachment, and proliferation in bone tissue engineering applications may be easily constructed with hybrid systems containing more than two types of materials. Here, we investigated the impact of adding GO to PPCNg with the goal of enhancing osteoinductive and osteoconductive properties. As a $2 \mathrm{D}$ crystal with one-atom thickness, graphene has become one of the hottest topics in materials science and nanotechnology. ${ }^{62}$ More recently, grapheme-based nanosheets have been considered as a fine nanofiller for the fabrication of hybrid scaffolds. ${ }^{55,59,61,63-65,68,69}$ We recently assembled gelatin-derived 

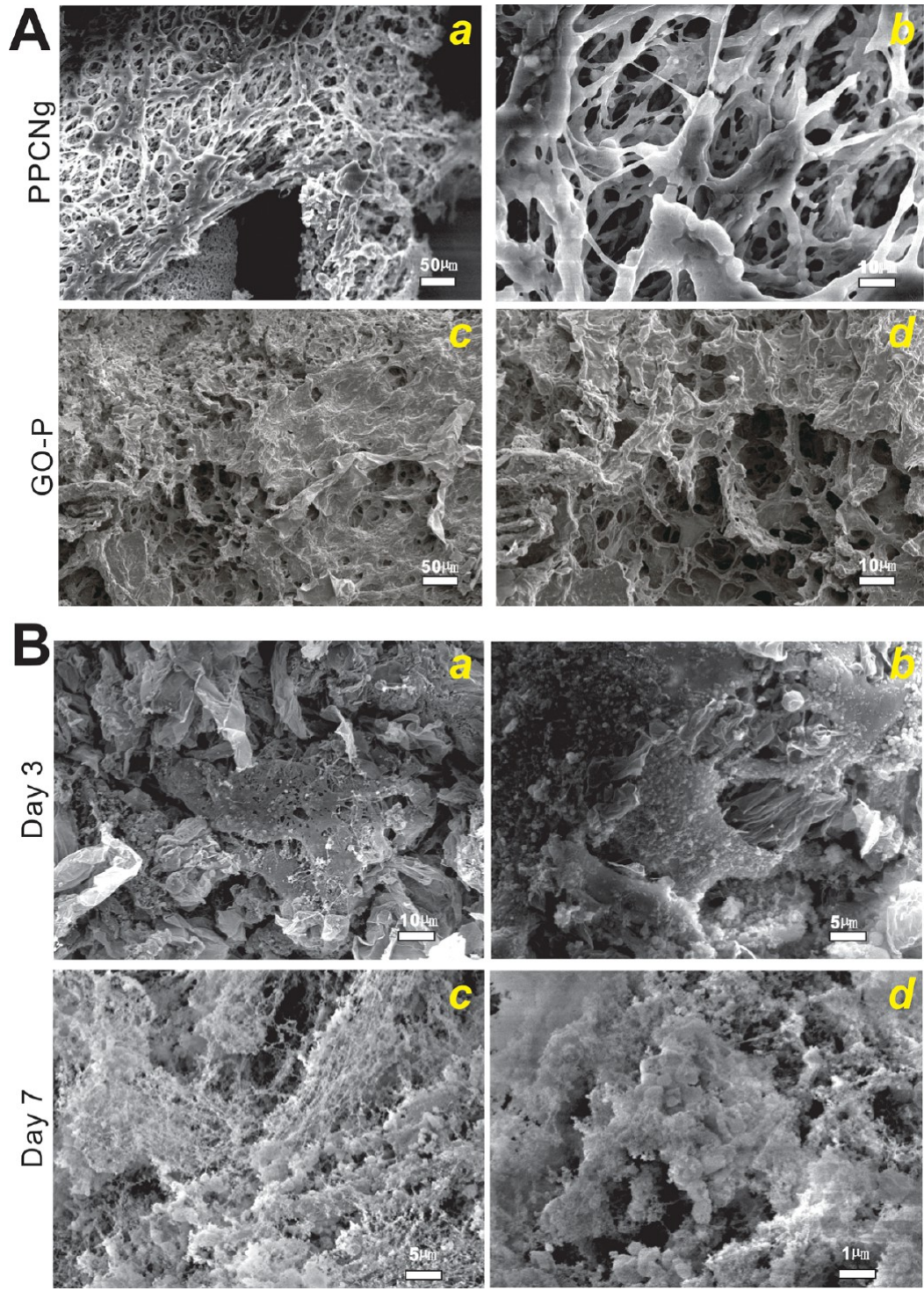

Figure 4. SEM analysis of the surface features of the scaffolds. SEM analysis of the PPCNg and GO-P scaffolds alone (A) or mixed with AdBMP9transduced iMADs (B) at day 3 and day 7 after seeding. Both lower magnifications (a and c) and higher magnifications (b and d) were taken. Representative images are shown.

graphene/laponite nanosheets using a cost-effective synthesis procedure. ${ }^{53}$ We demonstrated that the GL scaffold is biocompatible for supporting long-term proliferation of MSCs. ${ }^{53}$ The carbonized GL-powder hybrids were shown to effectively enhance BMP9-induced osteoblastic differentiation of MSCs in vitro and promote BMP9-induced bone formation in vivo, indicating that the addition of carbonized GL hybrids to BMP9stimulated MSCs can lead to more effective bone formation in vivo. ${ }^{53}$ Nonetheless, the nanosheet or powder nature of the GL-hybrid scaffold possesses fabrication challenges as biomaterials for stem cell-based tissue engineering.

The GO-P hybrid scaffold may provide an ideal osteogenic and angiogenic microenvironment for BMP9-transduced MSCbased bone tissue engineering. Here, we took advantage of the favorable physical properties of GO and sought to develop a hybrid scaffold by incorporating GO into the thermoresponsive PPCNg hydrogel. We showed that the addition of GO changes the viscoelastic properties of the PPCNg. The GO-P hybrid material is osteoinductive in vitro and significantly enhances the formation of more mature, better mineralized, and highly vascularized trabecular bone in vivo, indicating that the GO-P hybrid scaffold may provide a progenitor cell-friendly and osteogenic and angiogenic microenvironment for new bone formation. Furthermore, it is conceivable that the thermoresponsive property renders the GO-P flexible utility for being used as an injectable material to deliver MSC-containing constructs for bone regeneration. Taken together, our findings suggest that the GO-P hybrid material may function as a novel biocompatible and injectable scaffold with osteoinductive and osteoconductive activities to support the formation of new vascularized bone.

Nonetheless, our studies have several limitations. First, the GO-P scaffold should be further tested for osteogenic efficiency in segmental defect and/or fracture healing animal models. Second, the mix ratios between GO and PPCNg should be further assessed in vivo to maximize the osteoinductive and osteoconductive activities of GO-P scaffold. Third, the longterm biocompatibility and biosafety of GO-P scaffold materials should be extensively analyzed in vivo. Lastly, the exact mechanism through which GO itself induces osteogenic differentiation in MSCs needs to be elucidated. Therefore, 

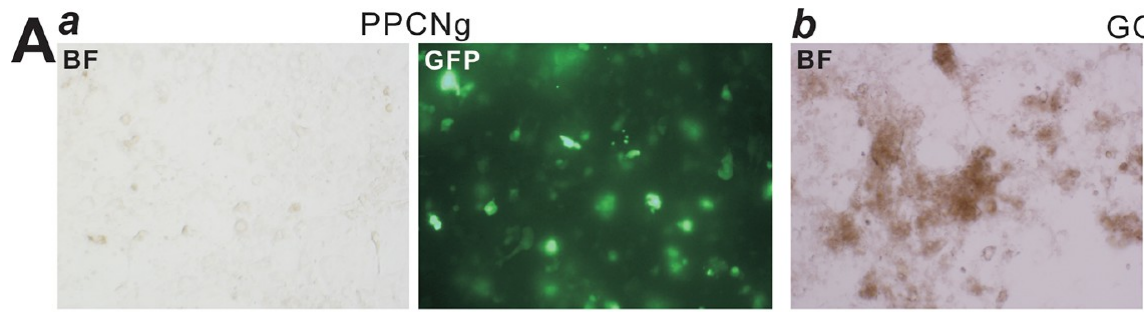

GO-P
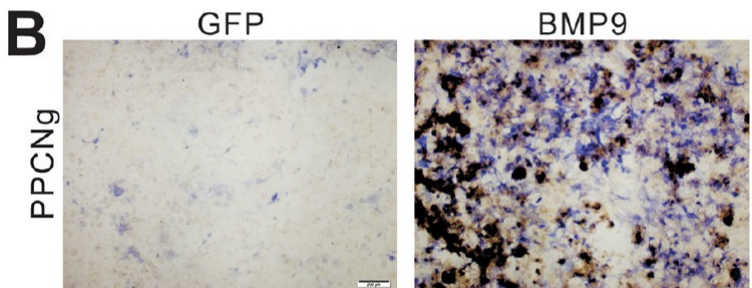

C
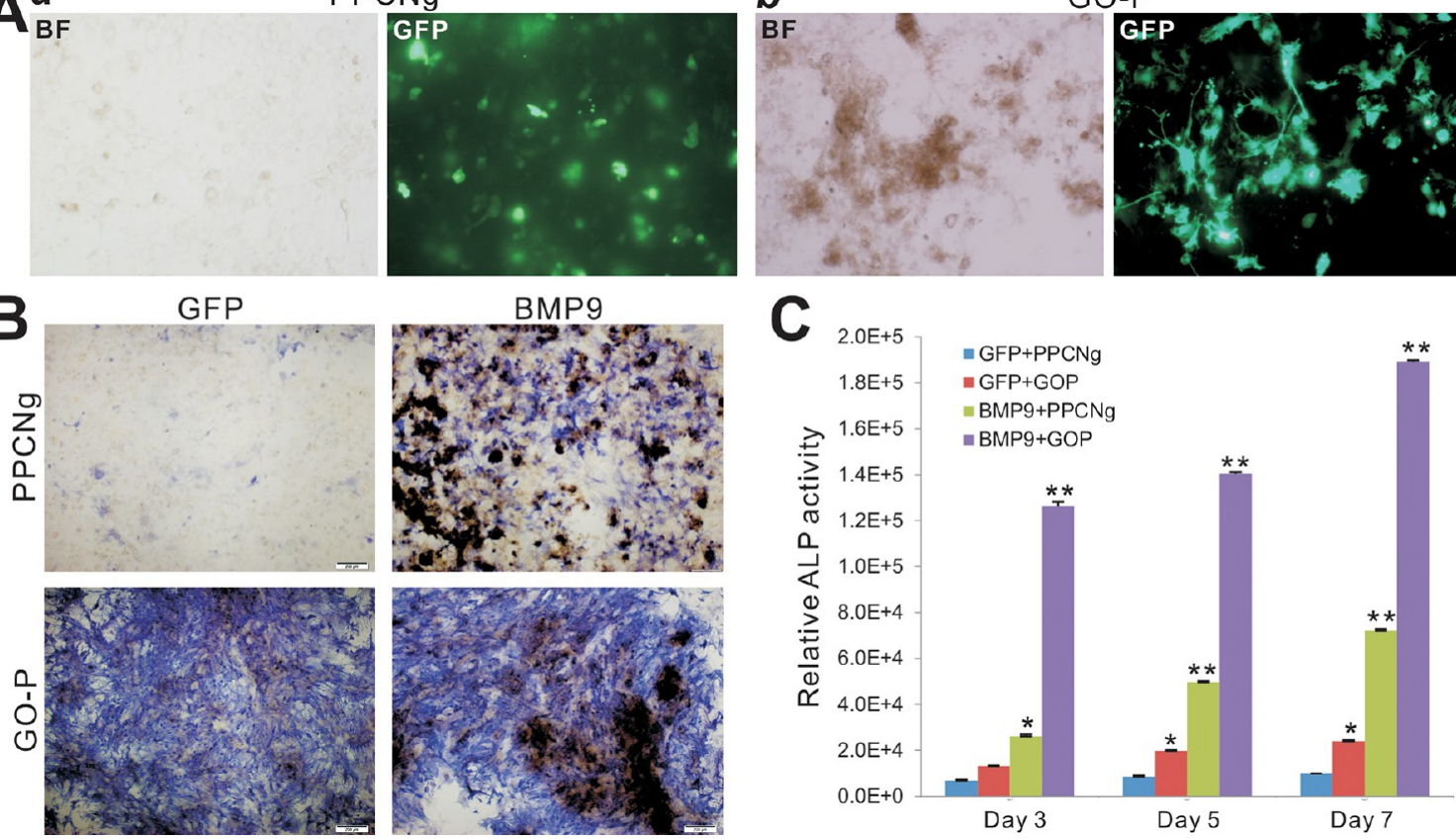

Figure 5. Osteoinductive and osteoconductive activities of the GO-P hybrid scaffold in vitro. (A) AdGFP or AdBMP9-infected iMADs were mixed with PPCNg (a) or GO-P (b) and examined at $48 \mathrm{~h}$ after infection under bright field (BF) or GFP fluorescence microscope (GFP). Representative images are shown. (B and C) ALP activity analysis. AdGFP or AdBMP9-transduced iMADs were mixed with PPCNg or GO-P and seeded in 24-well plates. ALP staining was carried out on day 5 (B), while quantitative ALP assay was conducted at 3, 5, and 7 days after infection (C). All assays were done in triplicate. ${ }^{*} p<0.05$ and $* * p<0.01$ when compared to respective GFP groups.

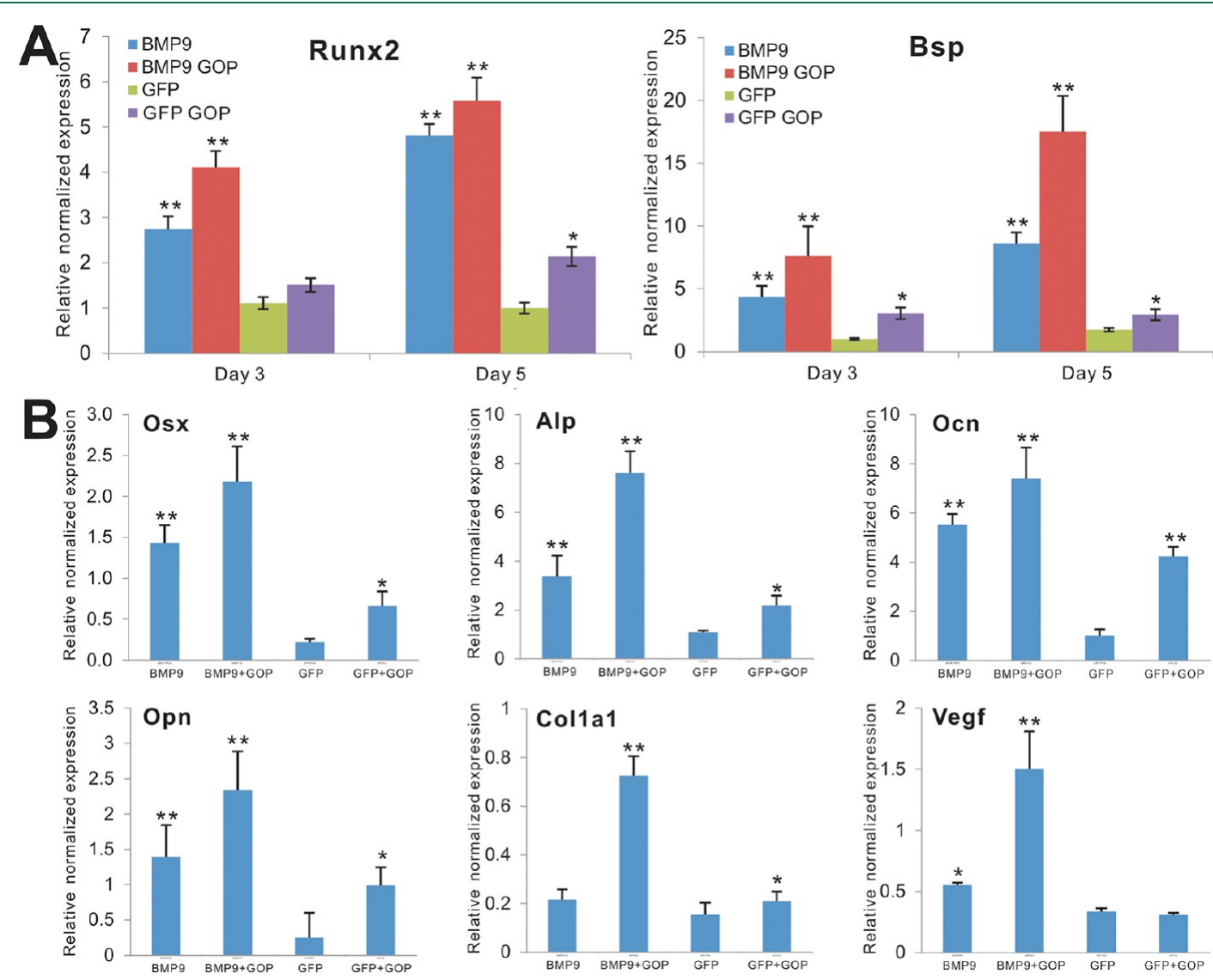

Figure 6. GO-P hybrid scaffold potentiates BMP9-induced expression of osteogenic regulators/markers and angiogenic regulator VEGF. Subconfluent iMAD cells were infected with Ad-GFP or Ad-BMP9 and mixed with PPCNg or GO-P. Total RNA was isolated at day 3 and day 5 and subjected to TqPCR analysis using gene-specific primers for mouse Runx2 and Bsp (A) and bone markers including Osx, Alp, Ocn, Opn, Colla1, and angiogenic regulator VEGF (day 5 only) (B). All assays were done in triplicate. $* p<0.05$ and $* * p<0.01$ when compared to respective GFP groups. 


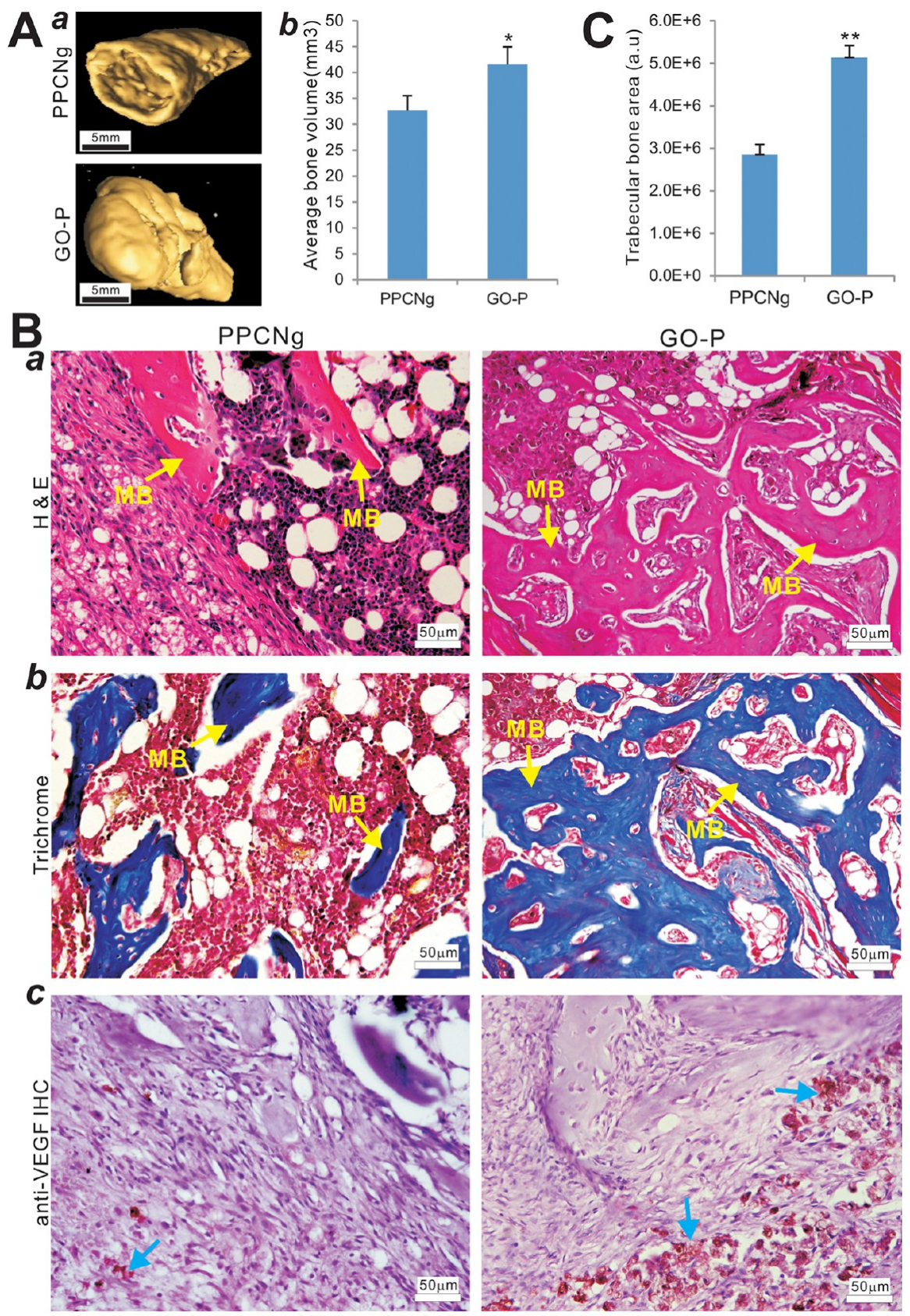

Figure 7. GO-P hybrid scaffold augments BMP9-induced ectopic bone formation. AdBMP9-transduced iMADs were mixed with PPCNg or GO-P scaffold and subcutaneously injected into the flanks of athymic nude mice for four weeks. Bony masses were retrieved and subjected to $\mu \mathrm{CT}$ imaging (A, a and $\mathrm{b})$, followed by H\&E staining (B, a), trichrome staining (B, b), and anti-VEGF immunohistochemical staining (B, c). Representative images are shown. Yellow arrows indicate representative mature/fully mineralized bone (MB), while blue arrows indicate representative VEGF-positive cells. (C) The average areas of trabecular bone were quantitatively determined by measuring more than 10 high-power fields using the ImageJ software $(\mathrm{C})$. ** $p<0.01$.

future directions should focus on overcoming these limitations so that the GO-P hybrid material can be translated into possible preclinical and clinical bone tissue engineering applications.

\section{CONCLUSION}

In our search for highly biocompatible, osteoinductive and osteoconductive scaffolds, we investigated whether incorporating GO into PPCNg would enhance its ability to support the formation of new bone. We demonstrated that the addition of GO maintains thermoresponsive behavior of the hybrid material and effectively supported MSC survival and proliferation. Furthermore, GO-P induced ALP and potentiates BMP9regulated expression of osteogenic regulators and bone forming markers as well as the angiogenic factor VEGF in MSCs. We further showed that BMP9-transduced MSCs entrapped in the GO-P scaffold form well-mineralized and highly vascularized trabecular bone in vivo. Thus, our findings demonstrate that the GO-P hybrid material may be used as a novel biocompatible and injectable scaffold with osteoinductive and osteoconductive activities to support the formation of new vascularized bone.

\section{ASSOCIATED CONTENT}

\section{S Supporting Information}

The Supporting Information is available free of charge on the ACS Publications website at DOI: 10.1021/acsbiomaterials.8b00179. 
Table S1: list of qPCR primers; Figure S1: Effect of PPCN:GO compositions on the temperature evolution of the viscoelastic properties (PDF)

\section{AUTHOR INFORMATION}

\section{Corresponding Authors}

*Tel.: (773) 702-7169; Fax: (773) 834-4598; E-mail: tche@ uchicago.edu.

*Tel./Fax: (86)23- 89011212; E-mail: huangwei68@263.net. ORCID

Tong-Chuan He: 0000-0001-7721-3934

\section{Author Contributions}

T.C.H., W.H., C.Z., R.R.R., G.A.A., J.M.W., M.J.L., A.A., and L.O. conceived and designed the study. C.Z., Z.Z., N.T.Q., X.Y., R.Z., and S. Yan performed most experiments and collected data. Y. Shu, Y.Z., C.D., E.B., J.L., W.Z., C. Yang, K.W., Y.W., L.A., S.H., X.J., C.G., C. Yuan, L.Z., W. Liu, B.H., Y.F., B.Z., Z.D., Y. Shen, X.W., and W. Luo provided essential experimental materials (such as adenovirus construction and high titer amplification), and assisted in SEM sample preparation and analysis, histological preparations, immune-staining, and qPCR data analysis and interpretations. T.C.H., C.Z., N.T.Q., W.H., C.Z., R.R.R., G.A.A., J.M.W., M.J.L., A.A., and L.O. drafted the manuscript. All authors reviewed and approved the manuscript.

Notes

The authors declare no competing financial interest.

\section{ACKNOWLEDGMENTS}

The reported work was supported in part by research grants from the National Institutes of Health (Grants CA226303 and DE020140 to T.C.H. and R.R.R.), the U.S. Department of Defense (Grant OR130096 to J.M.W.), the Chicago Biomedical Consortium with support from the Searle Funds at The Chicago Community Trust (R.R.R., T.C.H., and G.A.A.), the Scoliosis Research Society (T.C.H. and M.J.L.), the NIST CHiMAD (Grant 70NANB14H012 to N.T.Q.), the National Key Research and Development Program of China (Grants 2016YFC1000803 and 2011CB707906 to T.C.H.), and the National Natural Science Foundation of China (Grants 81371972 and 81572142 to W.H.). Z.Z., R.Z., Y.S., Y.W., W.Z., L.A., C.Y., B.H., Y.F., and B.Z. received scholarship funding from the China Scholarship Council. This project was also supported in part by The University of Chicago Cancer Center Support Grant (P30CA014599) and the National Center for Advancing Translational Sciences of the National Institutes of Health through Grant Number UL1 TR000430. In addition, the reported work utilized The University of Chicago's MRSEC Facilities, which are supported by the National Science Foundation (Grant NSF-DMR-1420709).

\section{REFERENCES}

(1) O'Keefe, R. J.; Mao, J. Bone tissue engineering and regeneration: from discovery to the clinic-an overview. Tissue Eng., Part B 2011, 17 (6), 389-392.

(2) Shrivats, A. R.; McDermott, M. C.; Hollinger, J. O. Bone tissue engineering: state of the union. Drug Discovery Today 2014, 19 (6), 781-786.

(3) Deng, Z. L.; Sharff, K. A.; Tang, N.; Song, W. X.; Luo, J.; Luo, X.; Chen, J.; Bennett, E.; Reid, R.; Manning, D.; Xue, A.; Montag, A. G.; Luu, H. H.; Haydon, R. C.; He, T. C. Regulation of osteogenic differentiation during skeletal development. Front Biosci 2008, 13, 2001-2021.
(4) Wang, R. N.; Green, J.; Wang, Z.; Deng, Y.; Qiao, M.; Peabody, M.; Zhang, Q.; Ye, J.; Yan, Z.; Denduluri, S.; Idowu, O.; Li, M.; Shen, C.; Hu, A.; Haydon, R. C.; Kang, R.; Mok, J.; Lee, M. J.; Luu, H. L.; Shi, L. L. Bone Morphogenetic Protein (BMP) signaling in development and human diseases. Genes Dis 2014, 1 (1), 87-105.

(5) Crane, G. M.; Ishaug, S. L.; Mikos, A. G. Bone tissue engineering. Nat. Med. 1995, 1 (12), 1322-1324.

(6) Szpalski, C.; Wetterau, M.; Barr, J.; Warren, S. M. Bone tissue engineering: current strategies and techniques-part I: Scaffolds. Tissue Eng., Part B 2012, 18 (4), 246-257.

(7) Luo, J.; Sun, M. H.; Kang, Q.; Peng, Y.; Jiang, W.; Luu, H. H.; Luo, Q.; Park, J. Y.; Li, Y.; Haydon, R. C.; He, T. C. Gene therapy for bone regeneration. Curr. Gene Ther. 2005, 5 (2), 167-179.

(8) Prockop, D. J. Marrow stromal cells as stem cells for nonhematopoietic tissues. Science 1997, 276 (5309), 71-74.

(9) Pittenger, M. F.; Mackay, A. M.; Beck, S. C.; Jaiswal, R. K.; Douglas, R.; Mosca, J. D.; Moorman, M. A.; Simonetti, D. W.; Craig, S.; Marshak, D. R. Multilineage potential of adult human mesenchymal stem cells. Science 1999, 284 (5411), 143-147.

(10) Rastegar, F.; Shenaq, D.; Huang, J.; Zhang, W.; Zhang, B. Q.; He, B. C.; Chen, L.; Zuo, G. W.; Luo, Q.; Shi, Q.; Wagner, E. R.; Huang, E.; Gao, Y.; Gao, J. L.; Kim, S. H.; Zhou, J. Z.; Bi, Y.; Su, Y.; Zhu, G.; Luo, J.; Luo, X.; Qin, J.; Reid, R. R.; Luu, H. H.; Haydon, R. C.; Deng, Z. L.; He, T. C. Mesenchymal stem cells: Molecular characteristics and clinical applications. World J. Stem Cells 2010, 2 (4), 67-80.

(11) Shenaq, D. S.; Rastegar, F.; Petkovic, D.; Zhang, B. Q.; He, B. C.; Chen, L.; Zuo, G. W.; Luo, Q.; Shi, Q.; Wagner, E. R.; Huang, E.; Gao, Y.; Gao, J. L.; Kim, S. H.; Yang, K.; Bi, Y.; Su, Y.; Zhu, G.; Luo, J.; Luo, X.; Qin, J.; Reid, R. R.; Luu, H. H.; Haydon, R. C.; He, T. C. Mesenchymal Progenitor Cells and Their Orthopedic Applications: Forging a Path towards Clinical Trials. Stem Cells Int. 2010, 2010, 519028 .

(12) Teven, C. M.; Liu, X.; Hu, N.; Tang, N.; Kim, S. H.; Huang, E.; Yang, K.; Li, M.; Gao, J. L.; Liu, H.; Natale, R. B.; Luther, G.; Luo, Q.; Wang, L.; Rames, R.; Bi, Y.; Luo, J.; Luu, H. H.; Haydon, R. C.; Reid, R. R.; He, T. C. Epigenetic regulation of mesenchymal stem cells: a focus on osteogenic and adipogenic differentiation. Stem Cells Int. 2011, 2011, 201371.

(13) Green, J. D.; Tollemar, V.; Dougherty, M.; Yan, Z.; Yin, L.; Ye, J.; Collier, Z.; Mohammed, M. K.; Haydon, R. C.; Luu, H. H.; Kang, R.; Lee, M. J.; Ho, S. H.; He, T. C.; Shi, L. L.; Athiviraham, A. Multifaceted signaling regulators of chondrogenesis: Implications in cartilage regeneration and tissue engineering. Genes Dis 2015, 2 (4), 307-327.

(14) Phinney, D. G.; Sensebe, L. Mesenchymal stromal cells: misconceptions and evolving concepts. Cytotherapy 2013, 15 (2), $140-145$.

(15) Sanchez-Gurmaches, J.; Guertin, D. A. Adipocyte lineages: tracing back the origins of fat. Biochim. Biophys. Acta, Mol. Basis Dis. 2014, 1842 (3), 340-351.

(16) Zeve, D.; Tang, W.; Graff, J. Fighting fat with fat: the expanding field of adipose stem cells. Cell Stem Cell 2009, 5 (5), 472-481.

(17) Berry, D. C.; Stenesen, D.; Zeve, D.; Graff, J. M. The developmental origins of adipose tissue. Development 2013, 140 (19), 3939-3949.

(18) Nordberg, R. C.; Loboa, E. G. Our Fat Future: Translating Adipose Stem Cell Therapy. Stem Cells Transl. Med. 2015, 4 (9), 974979.

(19) Kapur, S. K.; Dos-Anjos Vilaboa, S.; Llull, R.; Katz, A. J. Adipose tissue and stem/progenitor cells: discovery and development. Clin Plast Surg 2015, 42 (2), 155-167.

(20) Huang, S. J.; Fu, R. H.; Shyu, W. C.; Liu, S. P.; Jong, G. P.; Chiu, Y. W.; Wu, H. S.; Tsou, Y. A.; Cheng, C. W.; Lin, S. Z. Adipose-derived stem cells: isolation, characterization, and differentiation potential. Cell Transplant 2013, 22 (4), 701-709.

(21) Halvorsen, Y. C.; Wilkison, W. O.; Gimble, J. M. Adipose-derived stromal cells-their utility and potential in bone formation. Int. J. Obes. 2000, 24, S41-44.

(22) Zuk, P. A.; Zhu, M.; Mizuno, H.; Huang, J.; Futrell, J. W.; Katz, A. J.; Benhaim, P.; Lorenz, H. P.; Hedrick, M. H. Multilineage cells from 
human adipose tissue: implications for cell- based therapies. Tissue Eng. 2001, 7 (2), 211-228.

(23) Gimble, J. M.; Guilak, F. Differentiation potential of adipose derived adult stem (ADAS) cells. Curr. Top. Dev. Biol. 2003, 58, 137160.

(24) Lu, S.; Wang, J.; Ye, J.; Zou, Y.; Zhu, Y.; Wei, Q.; Wang, X.; Tang, S.; Liu, H.; Fan, J.; Zhang, F.; Farina, E. M.; Mohammed, M. M.; Song, D.; Liao, J.; Huang, J.; Guo, D.; Lu, M.; Liu, F.; Liu, J.; Li, L.; Ma, C.; Hu, X.; Lee, M. J.; Reid, R. R.; Ameer, G. A.; Zhou, D.; He, T. Bone morphogenetic protein 9 (BMP9) induces effective bone formation from reversibly immortalized multipotent adipose-derived (iMAD) mesenchymal stem cells. Am. J. Transl Res. 2016, 8 (9), 3710-3730.

(25) Raucci, A.; Bellosta, P.; Grassi, R.; Basilico, C.; Mansukhani, A. Osteoblast proliferation or differentiation is regulated by relative strengths of opposing signaling pathways. J. Cell. Physiol. 2008, 215 (2), $442-451$.

(26) Kim, J. H.; Liu, X.; Wang, J.; Chen, X.; Zhang, H.; Kim, S. H.; Cui, J.; Li, R.; Zhang, W.; Kong, Y.; Zhang, J.; Shui, W.; Lamplot, J.; Rogers, M. R.; Zhao, C.; Wang, N.; Rajan, P.; Tomal, J.; Statz, J.; Wu, N.; Luu, H. H.; Haydon, R. C.; He, T. C. Wnt signaling in bone formation and its therapeutic potential for bone diseases. Ther. Adv. Musculoskeletal Dis. 2013, 5 (1), 13-31.

(27) Yang, K.; Wang, X.; Zhang, H.; Wang, Z.; Nan, G.; Li, Y.; Zhang, F.; Mohammed, M. K.; Haydon, R. C.; Luu, H. H.; Bi, Y.; He, T. C. The evolving roles of canonical WNT signaling in stem cells and tumorigenesis: implications in targeted cancer therapies. Lab. Invest. 2016, 96 (2), 116-136.

(28) Denduluri, S. K.; Idowu, O.; Wang, Z.; Liao, Z.; Yan, Z.; Mohammed, M. K.; Ye, J.; Wei, Q.; Wang, J.; Zhao, L.; Luu, H. H. Insulin-like growth factor (IGF) signaling in tumorigenesis and the development of cancer drug resistance. Genes Dis 2015, 2 (1), 13-25.

(29) Teven, C. M.; Farina, E. M.; Rivas, J.; Reid, R. R. Fibroblast growth factor (FGF) signaling in development and skeletal diseases. Genes Dis 2014, 1 (2), 199-213.

(30) Jo, A.; Denduluri, S. K.; Zhang, B.; Wang, Z.; Yin, L.; Yan, Z.; Kang, R.; Shi, L. L.; Mok, J.; Lee, M. J.; Haydon, R. C. The Versatile Functions of Sox9 in Development, Stem Cells, and Human Diseases. Genes Dis 2014, 1 (2), 149-161.

(31) Louvi, A.; Artavanis-Tsakonas, S. Notch and disease: a growing field. Semin. Cell Dev. Biol. 2012, 23 (4), 473-480.

(32) Zanotti, S.; Canalis, E. Notch and the skeleton. Mol. Cell. Biol. 2010, 30 (4), 886-96.

(33) Guruharsha, K. G.; Kankel, M. W.; Artavanis-Tsakonas, S. The Notch signalling system: recent insights into the complexity of a conserved pathway. Nat. Rev. Genet. 2012, 13 (9), 654-666.

(34) Varga, A. C.; Wrana, J. L. The disparate role of BMP in stem cell biology. Oncogene 2005, 24 (37), 5713-5721.

(35) Luu, H. H.; Song, W. X.; Luo, X.; Manning, D.; Luo, J.; Deng, Z. L.; Sharff, K. A.; Montag, A. G.; Haydon, R. C.; He, T. C. Distinct roles of bone morphogenetic proteins in osteogenic differentiation of mesenchymal stem cells. J. Orthop. Res. 2007, 25 (5), 665-677.

(36) Cheng, H.; Jiang, W.; Phillips, F. M.; Haydon, R. C.; Peng, Y.; Zhou, L.; Luu, H. H.; An, N.; Breyer, B.; Vanichakarn, P.; Szatkowski, J. P.; Park, J. Y.; He, T. C. Osteogenic activity of the fourteen types of human bone morphogenetic proteins (BMPs). J. Bone Joint Surg Am. 2003, 85-A (8), 1544-1552.

(37) Kang, Q.; Sun, M. H.; Cheng, H.; Peng, Y.; Montag, A. G.; Deyrup, A. T.; Jiang, W.; Luu, H. H.; Luo, J.; Szatkowski, J. P.; Vanichakarn, P.; Park, J. Y.; Li, Y.; Haydon, R. C.; He, T. C. Characterization of the distinct orthotopic bone-forming activity of 14 BMPs using recombinant adenovirus-mediated gene delivery. Gene Ther. 2004, 11 (17), 1312-1320.

(38) Luther, G.; Wagner, E. R.; Zhu, G.; Kang, Q.; Luo, Q.; Lamplot, J.; Bi, Y.; Luo, X.; Luo, J.; Teven, C.; Shi, Q.; Kim, S. H.; Gao, J. L.; Huang, E.; Yang, K.; Rames, R.; Liu, X.; Li, M.; Hu, N.; Liu, H.; Su, Y.; Chen, L.; He, B. C.; Zuo, G. W.; Deng, Z. L.; Reid, R. R.; Luu, H. H.; Haydon, R. C.; He, T. C. BMP-9 induced osteogenic differentiation of mesenchymal stem cells: molecular mechanism and therapeutic potential. Curr. Gene Ther. 2011, 11 (3), 229-240.
(39) Lamplot, J. D.; Qin, J.; Nan, G.; Wang, J.; Liu, X.; Yin, L.; Tomal, J.; Li, R.; Shui, W.; Zhang, H.; Kim, S. H.; Zhang, W.; Zhang, J.; Kong, Y.; Denduluri, S.; Rogers, M. R.; Pratt, A.; Haydon, R. C.; Luu, H. H.; Angeles, J.; Shi, L. L.; He, T. C. BMP9 signaling in stem cell differentiation and osteogenesis. Am. J. Stem Cells 2013, 2 (1), 1-21.

(40) Peng, Y.; Kang, Q.; Cheng, H.; Li, X.; Sun, M. H.; Jiang, W.; Luu, H. H.; Park, J. Y.; Haydon, R. C.; He, T. C. Transcriptional characterization of bone morphogenetic proteins (BMPs)-mediated osteogenic signaling. J. Cell. Biochem. 2003, 90 (6), 1149-1165.

(41) Peng, Y.; Kang, Q.; Luo, Q.; Jiang, W.; Si, W.; Liu, B. A.; Luu, H. H.; Park, J. K.; Li, X.; Luo, J.; Montag, A. G.; Haydon, R. C.; He, T. C. Inhibitor of DNA binding/differentiation helix-loop-helix proteins mediate bone morphogenetic protein-induced osteoblast differentiation of mesenchymal stem cells. J. Biol. Chem. 2004, 279 (31), 32941-32949.

(42) Luo, Q.; Kang, Q.; Si, W.; Jiang, W.; Park, J. K.; Peng, Y.; Li, X.; Luu, H. H.; Luo, J.; Montag, A. G.; Haydon, R. C.; He, T. C. Connective Tissue Growth Factor (CTGF) Is Regulated by Wnt and Bone Morphogenetic Proteins Signaling in Osteoblast Differentiation of Mesenchymal Stem Cells. J. Biol. Chem. 2004, 279 (53), 55958-55968.

(43) Sharff, K. A.; Song, W. X.; Luo, X.; Tang, N.; Luo, J.; Chen, J.; Bi, Y.; He, B. C.; Huang, J.; Li, X.; Jiang, W.; Zhu, G. H.; Su, Y.; He, Y.; Shen, J.; Wang, Y.; Chen, L.; Zuo, G. W.; Liu, B.; Pan, X.; Reid, R. R.; Luu, H. H.; Haydon, R. C.; He, T. C. Hey1 Basic Helix-Loop-Helix Protein Plays an Important Role in Mediating BMP9-induced Osteogenic Differentiation of Mesenchymal Progenitor Cells. J. Biol. Chem. 2009, 284 (1), 649-659.

(44) Huang, E.; Zhu, G.; Jiang, W.; Yang, K.; Gao, Y.; Luo, Q.; Gao, J. L.; Kim, S. H.; Liu, X.; Li, M.; Shi, Q.; Hu, N.; Wang, L.; Liu, H.; Cui, J.; Zhang, W.; Li, R.; Chen, X.; Kong, Y. H.; Zhang, J.; Wang, J.; Shen, J.; Bi, Y.; Statz, J.; He, B. C.; Luo, J.; Wang, H.; Xiong, F.; Luu, H. H.; Haydon, R. C.; Yang, L.; He, T. C. Growth hormone synergizes with BMP9 in osteogenic differentiation by activating the JAK/STAT/IGF1 pathway in murine multilineage cells. J. Bone Miner. Res. 2012, 27 (7), $1566-1575$

(45) Liao, J.; Yu, X.; Hu, X.; Fan, J.; Wang, J.; Zhang, Z.; Zhao, C.; Zeng, Z.; Shu, Y.; Zhang, R.; Yan, S.; Li, Y.; Zhang, W.; Cui, J.; Ma, C.; Li, L.; Yu, Y.; Wu, T.; Wu, X.; Lei, J.; Wang, J.; Yang, C.; Wu, K.; Wu, Y.; Tang, J.; He, B. C.; Deng, Z. L.; Luu, H. H.; Haydon, R. C.; Reid, R. R.; Lee, M. J.; Wolf, J. M.; Huang, W.; He, T. C. lncRNA H19 mediates BMP9-induced osteogenic differentiation of mesenchymal stem cells (MSCs) through Notch signaling. Oncotarget 2017, 8 (32), 5358153601.

(46) Tang, N.; Song, W. X.; Luo, J.; Luo, X.; Chen, J.; Sharff, K. A.; Bi, Y.; He, B. C.; Huang, J. Y.; Zhu, G. H.; Su, Y. X.; Jiang, W.; Tang, M.; He, Y.; Wang, Y.; Chen, L.; Zuo, G. W.; Shen, J.; Pan, X.; Reid, R. R.; Luu, H. H.; Haydon, R. C.; He, T. C. BMP9-induced osteogenic differentiation of mesenchymal progenitors requires functional canonical Wnt/beta-catenin signaling. J. Cell Mol. Med. 2009, 13 (8B), 24482464.

(47) Chen, L.; Jiang, W.; Huang, J.; He, B. C.; Zuo, G. W.; Zhang, W.; Luo, Q.; Shi, Q.; Zhang, B. Q.; Wagner, E. R.; Luo, J.; Tang, M.; Wietholt, C.; Luo, X.; Bi, Y.; Su, Y.; Liu, B.; Kim, S. H.; He, C. J.; Hu, Y.; Shen, J.; Rastegar, F.; Huang, E.; Gao, Y.; Gao, J. L.; Zhou, J. Z.; Reid, R. R.; Luu, H. H.; Haydon, R. C.; He, T. C.; Deng, Z. L. Insulin-like growth factor 2 (IGF-2) potentiates BMP-9-induced osteogenic differentiation and bone formation. J. Bone Miner. Res. 2010, 25 (11), 2447-2459.

(48) Zhang, W.; Deng, Z. L.; Chen, L.; Zuo, G. W.; Luo, Q.; Shi, Q.; Zhang, B. Q.; Wagner, E. R.; Rastegar, F.; Kim, S. H.; Jiang, W.; Shen, J.; Huang, E.; Gao, Y.; Gao, J. L.; Zhou, J. Z.; Luo, J.; Huang, J.; Luo, X.; Bi, Y.; Su, Y.; Yang, K.; Liu, H.; Luu, H. H.; Haydon, R. C.; He, T. C.; He, B. C. Retinoic acids potentiate BMP9-induced osteogenic differentiation of mesenchymal progenitor cells. PLoS One 2010, 5 (7), e11917.

(49) Hu, N.; Jiang, D.; Huang, E.; Liu, X.; Li, R.; Liang, X.; Kim, S. H.; Chen, X.; Gao, J. L.; Zhang, H.; Zhang, W.; Kong, Y. H.; Zhang, J.; Wang, J.; Shui, W.; Luo, X.; Liu, B.; Cui, J.; Rogers, M. R.; Shen, J.; Zhao, C.; Wang, N.; Wu, N.; Luu, H. H.; Haydon, R. C.; He, T. C.; Huang, W. BMP9-regulated angiogenic signaling plays an important 
role in the osteogenic differentiation of mesenchymal progenitor cells. J. Cell Sci. 2013, 126 (2), 532-541.

(50) Liu, X.; Qin, J.; Luo, Q.; Bi, Y.; Zhu, G.; Jiang, W.; Kim, S. H.; Li, M.; Su, Y.; Nan, G.; Cui, J.; Zhang, W.; Li, R.; Chen, X.; Kong, Y.; Zhang, J.; Wang, J.; Rogers, M. R.; Zhang, H.; Shui, W.; Zhao, C.; Wang, N.; Liang, X.; Wu, N.; He, Y.; Luu, H. H.; Haydon, R. C.; Shi, L. L.; Li, T.; He, T. C.; Li, M. Cross-talk between EGF and BMP9 signalling pathways regulates the osteogenic differentiation of mesenchymal stem cells. J. Cell Mol. Med. 2013, 17 (9), 1160-1172.

(51) Zhang, H.; Wang, J.; Deng, F.; Huang, E.; Yan, Z.; Wang, Z.; Deng, Y.; Zhang, Q.; Zhang, Z.; Ye, J.; Qiao, M.; Li, R.; Wang, J.; Wei, Q.; Zhou, G.; Luu, H. H.; Haydon, R. C.; He, T. C.; Deng, F. Canonical Wnt signaling acts synergistically on BMP9-induced osteo/odontoblastic differentiation of stem cells of dental apical papilla (SCAPs). Biomaterials 2015, 39, 145-154.

(52) Liao, J.; Wei, Q.; Zou, Y.; Fan, J.; Song, D.; Cui, J.; Zhang, W.; Zhu, Y.; Ma, C.; Hu, X.; Qu, X.; Chen, L.; Yu, X.; Zhang, Z.; Wang, C.; Zhao, C.; Zeng, Z.; Zhang, R.; Yan, S.; Wu, T.; Wu, X.; Shu, Y.; Lei, J.; Li, Y.; Luu, H. H.; Lee, M. J.; Reid, R. R.; Ameer, G. A.; Wolf, J. M.; He, T. C.; Huang, W. Notch Signaling Augments BMP9-Induced Bone Formation by Promoting the Osteogenesis-Angiogenesis Coupling Process in Mesenchymal Stem Cells (MSCs). Cell. Physiol. Biochem. 2017, 41 (5), 1905-1923.

(53) Zou, Y.; Qazvini, N. T.; Zane, K.; Sadati, M.; Wei, Q.; Liao, J.; Fan, J.; Song, D.; Liu, J.; Ma, C.; Qu, X.; Chen, L.; Yu, X.; Zhang, Z.; Zhao, C.; Zeng, Z.; Zhang, R.; Yan, S.; Wu, T.; Wu, X.; Shu, Y.; Li, Y.; Zhang, W.; Reid, R. R.; Lee, M. J.; Wolf, J. M.; Tirrell, M.; He, T. C.; de Pablo, J. J.; Deng, Z. L. Gelatin-Derived Graphene-Silicate Hybrid Materials Are Biocompatible and Synergistically Promote BMP9Induced Osteogenic Differentiation of Mesenchymal Stem Cells. ACS Appl. Mater. Interfaces 2017, 9 (19), 15922-15932.

(54) Bose, S.; Roy, M.; Bandyopadhyay, A. Recent advances in bone tissue engineering scaffolds. Trends Biotechnol. 2012, 30 (10), 546554.

(55) Shin, Y. C.; Song, S. J.; Hong, S. W.; Jeong, S. J.; Chrzanowski, W.; Lee, J. C.; Han, D. W. Multifaceted Biomedical Applications of Functional Graphene Nanomaterials to Coated Substrates, Patterned Arrays and Hybrid Scaffolds. Nanomaterials 2017, 7 (11), 369.

(56) Gurunathan, S.; Kim, J. H. Synthesis, toxicity, biocompatibility, and biomedical applications of graphene and graphene-related materials. Int. J. Nanomed. 2016, 11, 1927-1945.

(57) Duran, N.; Martinez, D. S.; Silveira, C. P.; Duran, M.; de Moraes, A. C.; Simoes, M. B.; Alves, O. L.; Favaro, W. J. Graphene oxide: a carrier for pharmaceuticals and a scaffold for cell interactions. Curr. Top. Med. Chem. 2015, 15 (4), 309-327.

(58) Wu, S. Y.; An, S. S.; Hulme, J. Current applications of graphene oxide in nanomedicine. Int. J. Nanomed. 2015, 10, 9-24.

(59) Lalwani, G.; D’Agati, M.; Gopalan, A.; Rao, M.; Schneller, J.; Sitharaman, B. Three-dimensional macroporous graphene scaffolds for tissue engineering. J. Biomed. Mater. Res., Part A 2017, 105 (1), 73-83.

(60) Shadjou, N.; Hasanzadeh, M. Graphene and its nanostructure derivatives for use in bone tissue engineering: Recent advances. $J$. Biomed. Mater. Res., Part A 2016, 104 (5), 1250-1275.

(61) Shin, S. R.; Li, Y. C.; Jang, H. L.; Khoshakhlagh, P.; Akbari, M.; Nasajpour, A.; Zhang, Y. S.; Tamayol, A.; Khademhosseini, A. Graphene-based materials for tissue engineering. Adv. Drug Delivery Rev. 2016, 105, 255-274.

(62) Wang, Y.; Li, Z.; Wang, J.; Li, J.; Lin, Y. Graphene and graphene oxide: biofunctionalization and applications in biotechnology. Trends Biotechnol. 2011, 29 (5), 205-212.

(63) Li, D.; Zhang, W.; Yu, X.; Wang, Z.; Su, Z.; Wei, G. When biomolecules meet graphene: from molecular level interactions to material design and applications. Nanoscale 2016, 8 (47), 1949119509.

(64) Menaa, F.; Abdelghani, A.; Menaa, B. Graphene nanomaterials as biocompatible and conductive scaffolds for stem cells: impact for tissue engineering and regenerative medicine. J. Tissue Eng. Regener. Med. 2015, 9 (12), 1321-1338.
(65) Goenka, S.; Sant, V.; Sant, S. Graphene-based nanomaterials for drug delivery and tissue engineering. J. Controlled Release 2014, 173, $75-88$.

(66) Zhou, X.; Liang, F. Application of graphene/graphene oxide in biomedicine and biotechnology. Curr. Med. Chem. 2014, 21 (7), 855869.

(67) Liu, J.; Cui, L.; Losic, D. Graphene and graphene oxide as new nanocarriers for drug delivery applications. Acta Biomater. 2013, 9 (12), 9243-9257.

(68) Krishna, K. V.; Menard-Moyon, C.; Verma, S.; Bianco, A. Graphene-based nanomaterials for nanobiotechnology and biomedical applications. Nanomedicine (London, U. K.) 2013, 8 (10), 1669-1688.

(69) Ding, X.; Liu, H.; Fan, Y. Graphene-Based Materials in Regenerative Medicine. Adv. Healthcare Mater. 2015, 4 (10), 14511468.

(70) Yang, J.; van Lith, R.; Baler, K.; Hoshi, R. A.; Ameer, G. A. A thermoresponsive biodegradable polymer with intrinsic antioxidant properties. Biomacromolecules 2014, 15 (11), 3942-3952.

(71) Ye, J.; Wang, J.; Zhu, Y.; Wei, Q.; Wang, X.; Yang, J.; Tang, S.; Liu, H.; Fan, J.; Zhang, F.; Farina, E. M.; Mohammed, M. K.; Zou, Y.; Song, D.; Liao, J.; Huang, J.; Guo, D.; Lu, M.; Liu, F.; Liu, J.; Li, L.; Ma, C.; Hu, X.; Haydon, R. C.; Lee, M. J.; Reid, R. R.; Ameer, G. A.; Yang, L.; He, T. C. A thermoresponsive polydiolcitrate-gelatin scaffold and delivery system mediates effective bone formation from BMP9transduced mesenchymal stem cells. Biomed Mater. 2016, 11 (2), 025021 .

(72) Wu, N.; Zhang, H.; Deng, F.; Li, R.; Zhang, W.; Chen, X.; Wen, S.; Wang, N.; Zhang, J.; Yin, L.; Liao, Z.; Zhang, Z.; Zhang, Q.; Yan, Z.; Liu, W.; Wu, D.; Ye, J.; Deng, Y.; Yang, K.; Luu, H. H.; Haydon, R. C.; $\mathrm{He}, \mathrm{T}$. C. Overexpression of Ad5 precursor terminal protein accelerates recombinant adenovirus packaging and amplification in HEK-293 packaging cells. Gene Ther. 2014, 21 (7), 629-637.

(73) Wei, Q.; Fan, J.; Liao, J.; Zou, Y.; Song, D.; Liu, J.; Cui, J.; Liu, F.; Ma, C.; Hu, X.; Li, L.; Yu, Y.; Qu, X.; Chen, L.; Yu, X.; Zhang, Z.; Zhao, C.; Zeng, Z.; Zhang, R.; Yan, S.; Wu, X.; Shu, Y.; Reid, R. R.; Lee, M. J.; Wolf, J. M.; He, T. C. Engineering the Rapid Adenovirus Production and Amplification (RAPA) Cell Line to Expedite the Generation of Recombinant Adenoviruses. Cell. Physiol. Biochem. 2017, 41 (6), 23832398.

(74) He, T. C.; Zhou, S.; da Costa, L. T.; Yu, J.; Kinzler, K. W.; Vogelstein, B. A simplified system for generating recombinant adenoviruses. Proc. Natl. Acad. Sci. U. S. A. 1998, 95 (5), 2509-2514.

(75) Luo, J.; Deng, Z. L.; Luo, X.; Tang, N.; Song, W. X.; Chen, J.; Sharff, K. A.; Luu, H. H.; Haydon, R. C.; Kinzler, K. W.; Vogelstein, B.; $\mathrm{He}, \mathrm{T}$. C. A protocol for rapid generation of recombinant adenoviruses using the AdEasy system. Nat. Protoc. 2007, 2 (5), 1236-1247.

(76) Lee, C. S.; Bishop, E. S.; Zhang, R.; Yu, X.; Farina, E. M.; Yan, S.; Zhao, C.; Zheng, Z.; Shu, Y.; Wu, X.; Lei, J.; Li, Y.; Zhang, W.; Yang, C.; Wu, K.; Wu, Y.; Ho, S.; Athiviraham, A.; Lee, M. J.; Wolf, J. M.; Reid, R. R.; He, T. C. Adenovirus-Mediated Gene Delivery: Potential Applications for Gene and Cell-Based Therapies in the New Era of Personalized Medicine. Genes Dis 2017, 4 (2), 43-63.

(77) Chen, X.; Luther, G.; Zhang, W.; Nan, G.; Wagner, E. R.; Liao, Z.; Wu, N.; Zhang, H.; Wang, N.; Wen, S.; He, Y.; Deng, F.; Zhang, J.; Wu, D.; Zhang, B.; Haydon, R. C.; Zhou, L.; Luu, H. H.; He, T. C. The E-F hand calcium-binding protein S100A4 regulates the proliferation, survival and differentiation potential of human osteosarcoma cells. Cell. Physiol. Biochem. 2013, 32 (4), 1083-1096.

(78) Liao, Z.; Nan, G.; Yan, Z.; Zeng, L.; Deng, Y.; Ye, J.; Zhang, Z.; Qiao, M.; Li, R.; Denduluri, S.; Wang, J.; Wei, Q.; Geng, N.; Zhao, L.; Lu, S.; Wang, X.; Zhou, G.; Luu, H. H.; Haydon, R. C.; He, T. C.; Wang, Z. The Anthelmintic Drug Niclosamide Inhibits the Proliferative Activity of Human Osteosarcoma Cells by Targeting Multiple Signal Pathways. Curr. Cancer Drug Targets 2015, 15 (8), 726-738.

(79) Zhao, C.; Wu, N.; Deng, F.; Zhang, H.; Wang, N.; Zhang, W.; Chen, X.; Wen, S.; Zhang, J.; Yin, L.; Liao, Z.; Zhang, Z.; Zhang, Q.; Yan, Z.; Liu, W.; Wu, D.; Ye, J.; Deng, Y.; Zhou, G.; Luu, H. H.; Haydon, R. C.; Si, W.; He, T. C. Adenovirus-mediated gene transfer in 
mesenchymal stem cells can be significantly enhanced by the cationic polymer Polybrene. PLoS One 2014, 9 (3), e92908.

(80) Deng, Y.; Wang, Z.; Zhang, F.; Qiao, M.; Yan, Z.; Wei, Q.; Wang, J.; Liu, H.; Fan, J.; Zou, Y.; Liao, J.; Hu, X.; Chen, L.; Yu, X.; Haydon, R. C.; Luu, H. H.; Qi, H.; He, T. C.; Zhang, J. A Blockade of IGF Signaling Sensitizes Human Ovarian Cancer Cells to the Anthelmintic Niclosamide-Induced Anti-Proliferative and Anticancer Activities. Cell. Physiol. Biochem. 2016, 39 (3), 871-888.

(81) Deng, Y.; Zhang, J.; Wang, Z.; Yan, Z.; Qiao, M.; Ye, J.; Wei, Q.; Wang, J.; Wang, X.; Zhao, L.; Lu, S.; Tang, S.; Mohammed, M. K.; Liu, H.; Fan, J.; Zhang, F.; Zou, Y.; Liao, J.; Qi, H.; Haydon, R. C.; Luu, H. H.; He, T. C.; Tang, L. Antibiotic monensin synergizes with EGFR inhibitors and oxaliplatin to suppress the proliferation of human ovarian cancer cells. Sci. Rep. 2015, 5, 17523.

(82) Song, D.; Zhang, F.; Reid, R. R.; Ye, J.; Wei, Q.; Liao, J.; Zou, Y.; Fan, J.; Ma, C.; Hu, X.; Qu, X.; Chen, L.; Li, L.; Yu, Y.; Yu, X.; Zhang, Z.; Zhao, C.; Zeng, Z.; Zhang, R.; Yan, S.; Wu, T.; Wu, X.; Shu, Y.; Lei, J.; Li, Y.; Zhang, W.; Wang, J.; Lee, M. J.; Wolf, J. M.; Huang, D.; He, T. C. BMP9 induces osteogenesis and adipogenesis in the immortalized human cranial suture progenitors from the patent sutures of craniosynostosis patients. J. Cell Mol. Med. 2017, 21 (11), 2782-2795. (83) Zhang, Q.; Wang, J.; Deng, F.; Yan, Z.; Xia, Y.; Wang, Z.; Ye, J.; Deng, Y.; Zhang, Z.; Qiao, M.; Li, R.; Denduluri, S. K.; Wei, Q.; Zhao, L.; Lu, S.; Wang, X.; Tang, S.; Liu, H.; Luu, H. H.; Haydon, R. C.; He, T. C.; Jiang, L. TqPCR: A Touchdown qPCR Assay with Significantly Improved Detection Sensitivity and Amplification Efficiency of SYBR Green qPCR. PLoS One 2015, 10 (7), e0132666.

(84) Kang, Q.; Song, W. X.; Luo, Q.; Tang, N.; Luo, J.; Luo, X.; Chen, J.; Bi, Y.; He, B. C.; Park, J. K.; Jiang, W.; Tang, Y.; Huang, J.; Su, Y.; Zhu, G. H.; He, Y.; Yin, H.; Hu, Z.; Wang, Y.; Chen, L.; Zuo, G. W.; Pan, X.; Shen, J.; Vokes, T.; Reid, R. R.; Haydon, R. C.; Luu, H. H.; He, T. C. A comprehensive analysis of the dual roles of BMPs in regulating adipogenic and osteogenic differentiation of mesenchymal progenitor cells. Stem Cells Dev. 2009, 18 (4), 545-559.

(85) Wang, J.; Zhang, H.; Zhang, W.; Huang, E.; Wang, N.; Wu, N.; Wen, S.; Chen, X.; Liao, Z.; Deng, F.; Yin, L.; Zhang, J.; Zhang, Q.; Yan, Z.; Liu, W.; Zhang, Z.; Ye, J.; Deng, Y.; Luu, H. H.; Haydon, R. C.; He, T. C.; Deng, F. Bone Morphogenetic Protein-9 (BMP9) Effectively Induces Osteo/Odontoblastic Differentiation of the Reversibly Immortalized Stem Cells of Dental Apical Papilla. Stem Cells Dev. 2014, 23 (12), 1405-1416.

(86) Li, R.; Zhang, W.; Cui, J.; Shui, W.; Yin, L.; Wang, Y.; Zhang, H.; Wang, N.; Wu, N.; Nan, G.; Chen, X.; Wen, S.; Deng, F.; Zhou, G.; Liao, Z.; Zhang, J.; Zhang, Q.; Yan, Z.; Liu, W.; Zhang, Z.; Ye, J.; Deng, Y.; Luu, H. H.; Haydon, R. C.; He, T. C.; Deng, Z. L. Targeting BMP9promoted human osteosarcoma growth by inactivation of notch signaling. Curr. Cancer Drug Targets 2014, 14 (3), 274-285.

(87) Deng, F.; Chen, X.; Liao, Z.; Yan, Z.; Wang, Z.; Deng, Y.; Zhang, Q.; Zhang, Z.; Ye, J.; Qiao, M.; Li, R.; Denduluri, S.; Wang, J.; Wei, Q.; Li, M.; Geng, N.; Zhao, L.; Zhou, G.; Zhang, P.; Luu, H. H.; Haydon, R. C.; Reid, R. R.; Yang, T.; He, T. C. A simplified and versatile system for the simultaneous expression of multiple siRNAs in mammalian cells using Gibson DNA Assembly. PLoS One 2014, 9 (11), e113064.

(88) Lamplot, J. D.; Liu, B.; Yin, L.; Zhang, W.; Wang, Z.; Luther, G.; Wagner, E.; Li, R.; Nan, G.; Shui, W.; Yan, Z.; Rames, R.; Deng, F.; Zhang, H.; Liao, Z.; Liu, W.; Zhang, J.; Zhang, Z.; Zhang, Q.; Ye, J.; Deng, Y.; Qiao, M.; Haydon, R. C.; Luu, H. H.; Angeles, J.; Shi, L. L.; He, T. C.; Ho, S. H. Reversibly Immortalized Mouse Articular Chondrocytes Acquire Long-Term Proliferative Capability while Retaining Chondrogenic Phenotype. Cell Transplant 2015, 24 (6), $1053-1066$.

(89) Yan, Z.; Yin, L.; Wang, Z.; Ye, J.; Zhang, Z.; Li, R.; Denduluri, S. K.; Wang, J.; Wei, Q.; Zhao, L.; Lu, S.; Wang, X.; Tang, S.; Shi, L. L.; Lee, M. J.; He, T. C.; Deng, Z. L. A Novel Organ Culture Model of Mouse Intervertebral Disc Tissues. Cells Tissues Organs 2016, 201 (1), $38-50$.

(90) Haydon, R. C.; Deyrup, A.; Ishikawa, A.; Heck, R.; Jiang, W.; Zhou, L.; Feng, T.; King, D.; Cheng, H.; Breyer, B.; Peabody, T.; Simon, M. A.; Montag, A. G.; He, T. C. Cytoplasmic and/or nuclear accumulation of the beta-catenin protein is a frequent event in human osteosarcoma. Int. J. Cancer 2002, 102 (4), 338-342.

(91) Haydon, R. C.; Zhou, L.; Feng, T.; Breyer, B.; Cheng, H.; Jiang, W.; Ishikawa, A.; Peabody, T.; Montag, A.; Simon, M. A.; He, T. C. Nuclear receptor agonists as potential differentiation therapy agents for human osteosarcoma. Clin. Cancer Res. 2002, 8 (5), 1288-1294.

(92) Luther, G. A.; Lamplot, J.; Chen, X.; Rames, R.; Wagner, E. R.; Liu, X.; Parekh, A.; Huang, E.; Kim, S. H.; Shen, J.; Haydon, R. C.; He, T. C.; Luu, H. H. IGFBP5 Domains Exert Distinct Inhibitory Effects on the Tumorigenicity and Metastasis of Human Osteosarcoma. Cancer Lett. 2013, 336 (1), 222-230.

(93) Li, Y.; Wagner, E. R.; Yan, Z.; Wang, Z.; Luther, G.; Jiang, W.; Ye, J.; Wei, Q.; Wang, J.; Zhao, L.; Lu, S.; Wang, X.; Mohammed, M. K.; Tang, S.; Liu, H.; Fan, J.; Zhang, F.; Zou, Y.; Song, D.; Liao, J.; Haydon, R. C.; Luu, H. H.; He, T. C. The Calcium-Binding Protein S100A6 Accelerates Human Osteosarcoma Growth by Promoting Cell Proliferation and Inhibiting Osteogenic Differentiation. Cell. Physiol. Biochem. 2015, 37 (6), 2375-2392.

(94) Fan, J.; Wei, Q.; Liao, J.; Zou, Y.; Song, D.; Xiong, D.; Ma, C.; Hu, X.; Qu, X.; Chen, L.; Li, L.; Yu, Y.; Yu, X.; Zhang, Z.; Zhao, C.; Zeng, Z.; Zhang, R.; Yan, S.; Wu, T.; Wu, X.; Shu, Y.; Lei, J.; Li, Y.; Zhang, W.; Haydon, R. C.; Luu, H. H.; Huang, A.; He, T. C.; Tang, H. Noncanonical Wnt signaling plays an important role in modulating canonical Wnt-regulated stemness, proliferation and terminal differentiation of hepatic progenitors. Oncotarget 2017, 8 (16), 2710527119.

(95) Liao, J.; Wei, Q.; Fan, J.; Zou, Y.; Song, D.; Liu, J.; Liu, F.; Ma, C.; Hu, X.; Li, L.; Yu, Y.; Qu, X.; Chen, L.; Yu, X.; Zhang, Z.; Zhao, C.; Zeng, Z.; Zhang, R.; Yan, S.; Wu, T.; Wu, X.; Shu, Y.; Lei, J.; Li, Y.; Zhang, W.; Wang, J.; Reid, R. R.; Lee, M. J.; Huang, W.; Wolf, J. M.; He, T. C.; Wang, J. Characterization of retroviral infectivity and superinfection resistance during retrovirus-mediated transduction of mammalian cells. Gene Ther. 2017, 24 (6), 333-341. 